Andrews University

Digital Commons @ Andrews University

\title{
A Correlational Model of Burnout and Personality Among Clergy in the United States
}

Nathanael M. Stephens

Andrews University, stephenn@andrews.edu

Follow this and additional works at: https://digitalcommons.andrews.edu/dissertations

Part of the Educational Psychology Commons, and the Psychiatry and Psychology Commons

\section{Recommended Citation}

Stephens, Nathanael M., "A Correlational Model of Burnout and Personality Among Clergy in the United States" (2020). Dissertations. 1721.

https://digitalcommons.andrews.edu/dissertations/1721

https://dx.doi.org/10.32597/dissertations/1721

This Dissertation is brought to you for free and open access by the Graduate Research at Digital Commons @ Andrews University. It has been accepted for inclusion in Dissertations by an authorized administrator of Digital Commons@ Andrews University. For more information, please contact repository@andrews.edu. 


\begin{abstract}
A CORRELATIONAL STUDY OF BURNOUT AND PERSONALITY AMONG CLERGY IN THE UNITED STATES
\end{abstract}

by

Nathanael M. Stephens

Chair: Elvin Gabriel 


\section{ABSTRACT OF GRADUATE STUDENT RESEARCH}

Dissertation

Andrews University

School of Education

\section{Title: A CORRELATIONAL STUDY OF BURNOUT AND PERSONALITY AMONG CLERGY IN THE UNITED STATES}

Name of researcher: Nathanael M. Stephens, MA

Name and degree of faculty chair: Elvin Gabriel, Ed.D.

Date completed: July 13, 2018

\section{Problem}

This study explored the relationship between personality and burnout. The facets of personality detailed in the Factor Five Model served as the independent variables, with burnout as the dependent variable. Research exists on the relationship between personality and burnout for individuals in helping professions. However, there is little research on the interaction between burnout and personality factors among Protestant clergy members.

\section{Method}

A total of 602 participants who self-identified as living in the United States were recruited through an advertisement on Facebook. Participants all indicated they were Protestant members of the clergy and had been in the ministry for at least 6 years. Of the 
602 participants, $124(20.6 \%)$ were female and 478 (79.4) were male. One participant was under age $21(0.2 \%), 20$ were age 22 to $29(0.033 \%), 116$ were age 30 to $39(19.3 \%)$, 137 were age 40 to $49(22.8 \%), 191$ were age 50 to 59 (31.68\%), and 138 were age 60 or older $(31.68 \%)$. The questionnaire completed by participants consisted of items from the Maslach Burnout Inventory, the NEO Five-Factor Inventory, 3rd Edition (NEO-FFI-3), which measures the Big Five personality variables (i.e., neuroticism, extraversion, openness, agreeableness, and conscientiousness), as well as some demographic variables.

\section{Results}

Canonical correlational analysis was used to examine the relationships between the independent variables of personality traits (neuroticism, extraversion, openness, agreeableness, and conscientiousness) and components of the dependent variable, burnout (emotional exhaustion, personal accomplishment, and depersonalization). Through this analysis the relationship between the variables and the level of shared variance was determined. In addition, beta coefficients were used to confirm the extent to which variables on the independent canonical variate predicted the variables of the dependent canonical variate. The model was statistically significant, Wilks's $\lambda=0.317$, $F(15,1640.17)=56.477, p<.001, R_{c}=.759, R_{c}{ }^{2}=.577$, with moderate effect size.

\section{Conclusions}

According to Morgan and de Bruin (2010), there are strong links between personality and burnout, and the results of the present study suggested that this is also true for clergy members in the United States. Results of the present study indicated that personality traits collectively were moderately (.577) associated with burnout. In 
addition, it was found that the five personality variables (neuroticism, extraversion, openness, conscientiousness, and agreeableness) predicted depersonalization, emotional exhaustion, and feelings of personal accomplishment (to varying degrees).

For example, depersonalization was positively correlated with neuroticism $(\beta=$ $0.447)$ and negatively correlated with extraversion $(\beta=-0.073)$ and agreeableness $(\beta=-$ 0.269). Depersonalization was not significantly correlated with openness or conscientiousness. Emotional exhaustion was positively correlated with neuroticism $(\beta=$ $0.595)$ and conscientiousness $(\beta=0.069)$ and negatively correlated with extraversion $(\beta=$ -0.217). Emotional exhaustion was not significantly correlated with openness or agreeableness. Personal accomplishment was negatively correlated with neuroticism $(\beta=$ $-0.231)$ and positively associated with openness $(\beta=0.242)$, conscientiousness $(\beta=$ $0.181)$, and extraversion $(\beta=0.282)$. Personal accomplishment was not significantly correlated with agreeableness.

Keywords: Maslach Burnout Inventory, five-factor model, burnout, clergy, personality 
Andrews University

School of Education

\title{
A CORRELATIONAL MODEL OF BURNOUT AND PERSONALITY AMONG
} CLERGY IN THE UNITED STATES

\author{
A Dissertation \\ Presented in Partial Fulfillment \\ of the Requirements for the Degree \\ Doctor of Philosophy
}

by

Nathanael M. Stephens, MA

March 2020 
(C) Copyright by Nathanael M. Stephens 2020 All Rights Reserved 


\title{
A CORRELATIONAL STUDY OF BURNOUT AND PERSONALITY AMONG CLERGY IN THE UNITED STATES
}

\author{
A dissertation \\ presented in partial fulfillment \\ of the requirements for the degree \\ Doctor of Philosophy
}

by

Nathanael M. Stephens

\section{APPROVAL BY THE COMMITTEE:}

Chair: Elvin Gabriel, Ed.D.

Member: Tevni Grajales, Ph.D.

Member: Carole Woolford-Hunt, Ph.D.

External: Lionel Matthews, Ph.D.
Dean, School of Education

Alayne Thorpe

Date approved 
Dedicated to my parents, David and Kathryn Stephens, who have been unconditionally supportive; my brother, David James Stephens; and my best friend, David Alan Ewing (03/11/1985-09/28/2013), who I will miss for the rest of my life. Most importantly, to my Lord and Savior, Jesus Christ. 


\section{Acknowledgements}

I wish to thank my committee for their untiring work to help me bring this work to fruition. Specifically, I would like to thank my Chair, Dr. Elvin Gabriel for guiding my research from the very beginning. Additionally, Dr. Tevni Grajales was very instrumental in helping my structure my research to provide understandable results. Dr. Grajales was always very willing to help any time I asked and was able to brilliantly respond very quickly to any questions I had. Finally, Dr. Woolford-Hunt was both an integral part of my education and in the application of that education to my research. She is a passionate educator and encouraged me throughout the dissertation process. 
LIST OF TABLES ............................................................................................. vii

Chapter

1. INTRODUCTION AND BACKGROUND .............................................. 1

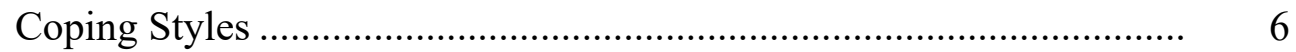

How Burnout Affects the Clergy …………………………………..... 14

Statement of the Problem ........................................................................ 17

Purpose of the Study ........................................................................... $\quad 19$

Research Questions ........................................................................... 20

Conceptual Framework ................................................................... 20

Conceptual Framework ................................................................... 20

Definition of Terms ......................................................................... 24

Organization of the Study ..................................................................... 25

2. REVIEW OF THE LITERATURE ………………………………........... 27

Brief Overview of Burnout .............................................................. 28

Theoretical Overview of Occupational Type Burnout........................... 31

An Exploration of the Research Between Personality and Burnout ...... 34

A Summary and Analysis of the Internal Structure of the MBI............ 36

The Emotional Exhaustion Dimension of the Maslach Burnout Inventory .............................................................................. 37

The Five-Factor Model and Its Relationship to Emotional

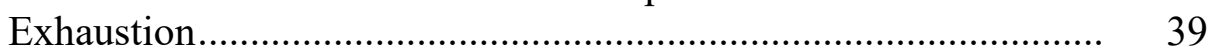

The Five-Factor Model And Its Relationship to Depersonalization ...... 41

The FFM And Its Relationship to Coping.............................................. 41

The Depersonalization Dimension of the MBI .................................... 42

Strengths of the Five-Factor Model ....................................................... 43

Weaknesses of the Five-Factor Model .................................................... 45

Cross-Cultural Generalizability of the Five-Factor Model .................... 47

Summary of the Theories and Models Related to Burnout.................... 47

Synthesis of the Literature Review ......................................................... 49

3. METHODOLOGY ……………………………….............................. 51

Type of Research............................................................................ 51

Population and Sample ...................................................................... 52

Hypotheses ................................................................................... 52

Definition of Variables ........................................................................ 53

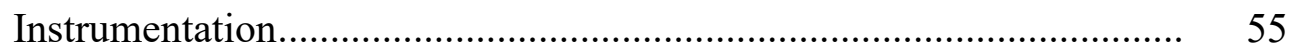

The Maslach Burnout Inventory............................................................ 55

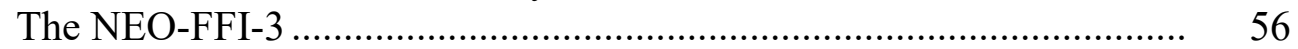

Data Collection ................................................................................ 57 


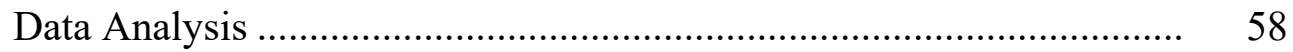

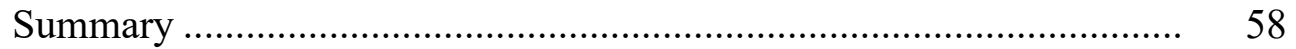

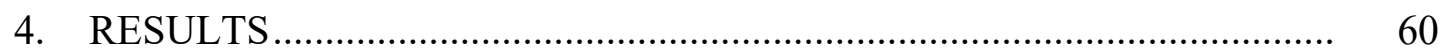

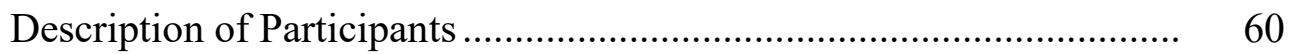

Description of Variables...................................................................... 63

Hypotheses Testing ......................................................................... 64

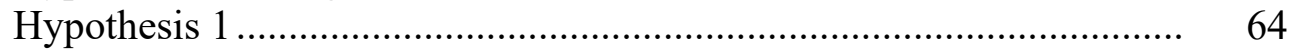

Research Hypothesis 1 .............................................................. 64

Null hypothesis. .................................................................... 64

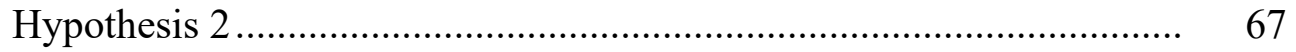

Null Hypothesis 2 ................................................................. 67

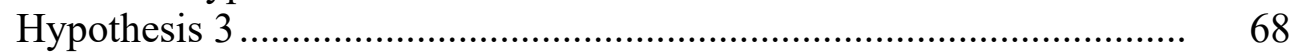

Null Hypothesis 3 .................................................................. 68

Hypothesis 4 ............................................................................... 69

Null Hypothesis 4 ................................................................. 69

Summary of Results ……………………...................................

5. SUMMARY DISCUSSION, CONCLUSIONS AND

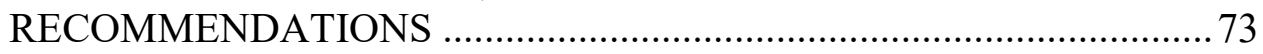

Purpose of the Study .........................................................................

Statement of the Problem ..................................................................... 74

Summary of the Literature Review ........................................................ 74

Historical and Philosophical Overview............................................... $\quad 75$

Summary of the Internal Structure of the MBI ..................................... 79

The Big Five/Five-Factor Model of Personality and its

Relationship to Depersonalization ................................................. 79

Methodology ............................................................................. 82

Population and Sample..................................................................... 82

Research Questions ...................................................................... 82

Research Design ............................................................................... 83

Summary of Findings ......................................................................... 83

Research Question 1 ....................................................................... 83

Hypothesis.......................................................................... 83

Results. ........................................................................ 83

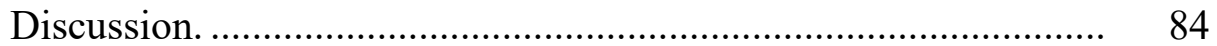

Research Question 2 ................................................................. 85

Hypothesis 2 .................................................................. 85

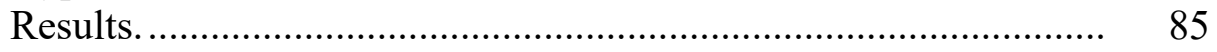

Discussion. ....................................................................... 86

Research Question 3 ............................................................... 86

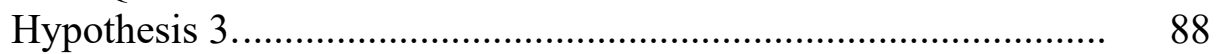

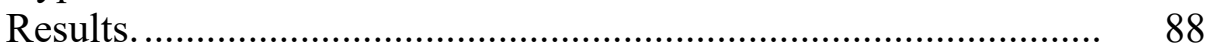

Discussion. ...................................................................... 88

Research Question 4 ...................................................................... 89 


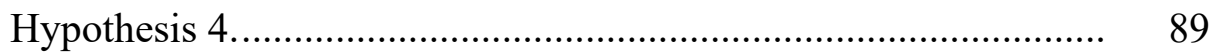

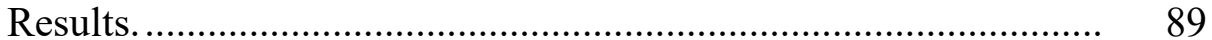

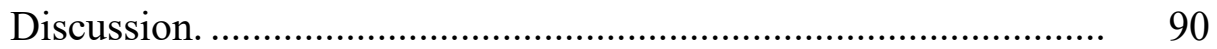

An Analysis of the Findings ........................................................... 90

Limitations of the Study .................................................................. 93

Implications for Further Research.................................................. 93

Implications for Practice ........................................................... 93

Appendix

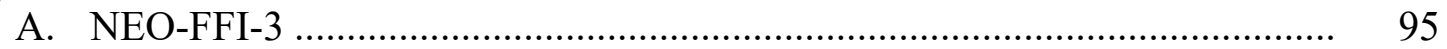

B. MASLACH BURNOUT INVENTORY ................................................. 98

C. STUDY WELCOME PAGE ........................................................... 101

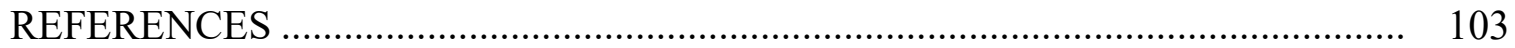




\section{LIST OF TABLES}

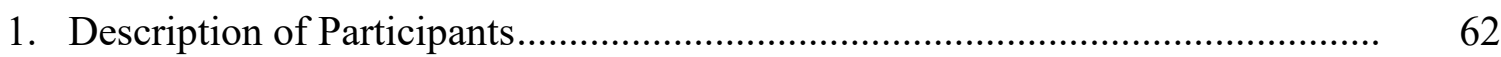

2. Descriptive Statistics of the Dimensions of Burnout and Personality .................. 63

3. Correlations Between Variables and Canonical Variates .................................. 66

4. Percentage of Explained Variance for Each Criterion Variable ........................ 67

5. Correlational Analysis Between Independent Variable (Depersonalization)

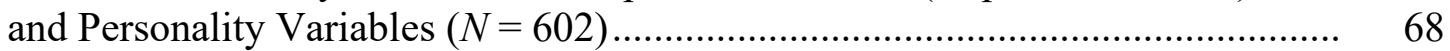

6. Correlational Analysis Between Independent Variable Emotional Exhaustion and Personality Variables $(N=602)$

7. Correlational Analysis Between Independent Variable Personal Accomplishment and Personality Variables $(N=602)$ 


\section{CHAPTER 1}

\section{INTRODUCTION AND BACKGROUND}

Based on research on the perspectives of workers in alternative health care organizations, Freudenberger connected burnout with stress and emotional and physical exhaustion (cited in Edwards, 2003). Burnout is associated with symptoms of malaise;

emotional, physical, and psychological fatigue; feelings of helplessness; hopelessness; a lack of enthusiasm about work; and even a lack of enthusiasm about life in general (Edwards, 2003).

According to Montero-Marin, et al (2014), the term burnout is often confused with stress. Burnout is a specific and separate concept, one that includes considerations of the length of time a person is employed in a particular job; expectations that person had when entering the job (and if these expectations were met); and levels of emotional exhaustion, depersonalization, and feelings of accomplishment experienced during that person's tenure on the job.

Many people enter the ministry without a full understanding of the stress and demands it will place on them. Some clergy members become successful and thrive, whereas others appear to struggle with functional performance. Why do some succeed while others fail? The answer may lie, among other things, in factors of personality. 
Christina Maslach developed the Maslach Burnout Inventory (MBI), (Maslach 1981) an assessment tool for measuring burnout. The MBI is grounded in the following definition of burnout "a state of physical, emotional helplessness and hopelessness and by the development of a negative self-concept and negative attitudes toward work, life, and other people" (Córdoba et al., 2011). This is the definition that guides the study.

(not in the bibliography) Homer (1985), observes that burnout results from overworking and the loss of personal equilibrium. Researchers have found for example that among Japanese physicians burnout (as measured by the MBI) correlated with depression (Saijo et al., 2014, p. 18). In one study, burnout made it more challenging for counselors in South Korea to manage countertransference (Choi, Puig, Kim, Lee, \& Lee, 2014).

(source) Others see burnout as a combination of exhaustion, cynicism, and inefficacy. Exhaustion involves feeling unable to offer more at the emotional level. Cynicism involves feeling distant towards one's work, over time. Inefficacy involves the feeling that one's work performance is inadequate or feelings of incompetence. These concepts are strongly correlated with one another (Schaufeli, Taris, \& van Rhenen, 2008). In this study, burnout is viewed as resulting from the length of time a person has been in a certain job; the expectations they had when starting the job; whether or not those were expectations met; and the levels of emotional exhaustion, depersonalization, and accomplishment that the person experienced in the occupation.

In the United States, the goal of many seminaries is to educate and prepare students by training them in Christian doctrine (Mitchell Legg, 2012). Selzer (2008) stated that many new professionals start a job with a great deal of "book knowledge" and 
extensive training to prepare them for their different job responsibilities and on "how best" to lead and administer a church However, many leave the seminary less able to successfully lead and minister (Selzer, 2008, p. 25). After inadequate preparation for the demands of their jobs, many new members of the clergy become disenchanted and lose their initial vision.

According to Barnatt et al. (2016), the primary cause of emotional exhaustion may be over-idealized goals. Oswald (2009) stated that as many as one in four clergy members suffer burnout. Joining the clergy can be stressful and may be conducive to burnout (Croucher, Marcenes, Torres, Hughes, \& Sheiham, 1997). Some enter the clergy with lofty goals (e.g., "saving the world") when they should instead focus on smaller, achievable goals. Clergy may set unreachable goals because they misunderstand organizational requirements or underestimate the effort necessary to achieve these goals. When clergy feel unable to achieve their own goals, they may begin to feel powerless, which can lead to discouragement, doubt, and obfuscation of vision. () (not in the bibliography and does not align with the rest of the paragraph). Burnout may also result in an individual not feeling accomplished on a personal level.

Burnout can also be self-inflicted and result from an ambiguous vision or mission statement, a lack of focus, or both (DePree, 2011). This author noted that "the first responsibility of a leader is to define reality" (p. 11). Bornstein and Smith (1996) stated that people should have a clear definition of the present and future and that they should listen to others and negotiate language. Zondag (2000) reported that clergy experiencing burnout have few individual or organizational support systems to help them. Improving support systems may prevent burnout in general. At the organizational level, there are 
few support systems to help clergy who have suffered burnout. Neither altruistic feelings nor a desire to live a Christian life fully protects a clergy member from the demands inherent in ministering to others.

Much of the research on burnout among members of the clergy has focused on attempts to explain why individuals entering the clergy start their positions with idealistic values and goals but then feel ineffective at reaching these goals. According to Miner, Dowson, and Sterland, (2010), "burnout is typically characterized by emotional exhaustion, depersonalization, and a reduced sense of personal accomplishment" (p. 167). Clergy members may experience stress when their goals and expectations are not fulfilled. Researchers of one study suggested that poor work-related psychological health among the Anglican ministry in Wales is related to "high levels of emotional exhaustion, high levels of Depersonalization, and low levels of personal accomplishment" (Berry, Francis, Rolph, \& Rolph, 2012, p p. 155-156).

Burnout refers to problems that are occupationally specific and which result in poor quality care for a minister's health and congregation members' well-being (Parker \& Martin, 2011).

One reason clergy quit ministering to others is because of an internal conflict between what they would like to see happen (their vision) and the reality of meeting the demands of their jobs. These demands can include expectations by congregants extending beyond holding worship services and delivering sermons (e.g., hospital visits, conflict resolution, pre-marriage counseling, presiding over weddings and funerals, and personal friendships), which can take a great deal of additional time and energy. Common ministerial demands include long hours for low pay, intrusion by congregants 
on the privacy of clergy members and their families, and ambiguous boundaries (C. Lee, 2010). Expectations of clergy to frequently help others may result in them suffering from compassion fatigue, a feeling of being tired of continually giving of themselves (Spencer, Winston, \& Bocarnea, 2012).

Other research by Tanner and Zvonkovic (2011) suggested that the high demands of ministering to others make it difficult for clergy members to adjust. Unrealistic demands upon clergy members (e.g., hospital visits in the middle of the night, interruptions from explosive family conflicts, and unpaid vacation), combined with high stress levels among clergy members of the Assemblies of God, recently forced some clergy members into early retirement (Tanner \& Zvonkovic, 2011). Even though members of the clergy experience significant stress, there is little understanding of clergy members' feelings about their overall quality of life. Clergy members in the United States are in a unique situation; people expect them to provide a broad range of services, including spiritual advice, emotional support, and even financial assistance (Justice \& Garland, 2010), and clergy members must provide these services even in the face of few resources and little support to facilitate their self-care (Pooler, 2011). Increasing levels of support may mediate clergy members' stress.

A growing body of research on the subject of burnout and factors contributing to this phenomena reveal that pastoring is demanding as well as emotionally exhausting; it is comparable to other high stress occupations, such as medical doctors working without pay, police officers without benefits, politicians without notoriety and political power, and occupations with very few vacations (Mueller \& McDuff, 2002). Mueller and 
McDuff (2002) asserted that the financial and time restraints on clergy can both be ambiguous and varying widely.

\section{Coping Styles}

Burnout affects everyone. It is important to recognize burnout and to develop effective coping mechanisms to deal with burnout symptoms. In an article entitled "Burnout in Christian Perspective," Frederick, Dunbar, and Thai (2018) highlighted mindfulness and Christian spirituality as mitigating factors that may help people to deal with burnout. They suggested that when Christians view their work as a "calling," it becomes a project of spiritual rejuvenation. According to Frederick et al. (2018), "the Christian spiritual practices of the Jesus prayer, the daily examen, and the prayer of condemnation are useful tools in assisting Christian human services workers to prevent and cope with burnout or compassion fatigue" (p. 1). The authors further noted that burnout and compassion fatigue are common among ministers and that discrepancies between the pastor's and the congregation's expectations of ministry was particularly important to burnout. They suggested that many pastors have difficulty differentiating between the self and the pastor's roles.

One study evaluated the effectiveness of a video module-based mindfulness training program (Goodman \& Boss, 2002). Medical doctors participating in this study showed significant increases in mindfulness skills and reported decreased stress and emotional exhaustion and an increased sense of personal accomplishment (Goodman \& Boss, 2002). Similarly, a study of psychologists found a robust negative correlation between mindfulness and burnout. The study revealed that four mindfulness facets- 
non-reactivity to inner experience, acting with awareness, describing, and non-judging of inner experience - were significantly and negatively correlated with burnout (Goodman \& Boss, 2002).

In Goodman and Boss's (2002) study, participants exhibited two broad types of mindfulness: concentration practice (which can effectively develop one's ability to concentrate and focus on the present moment) and insight practice (which allows one to attend to the experience). That is, insight practice allows a person to broaden their attention to any experience that arises while focusing on the present moment experience (Goodman \& Boss, 2002). Breath meditation, for example is a simple mindfulness technique that develops a person's concentration and focus. This practice involves intentionally experiencing one's breathing — noticing where in the body (nostrils, belly, and chest) the air fills and empties, as well as any smells or other sensations that arise with the breath (Goodman \& Boss, 2002).

For therapists, compassion fatigue can be very concerning because it can lead to a decreased ability to empathize with clients and thus limit the therapist's ability to create a healing relationship (Goodman \& Boss, 2002). Researchers have suggested mindfulness as a tool to decrease stress and burnout in health professionals; it may also increase practitioner compassion and improve patient relationships. Goodman and Boss (2002) found that the practice of mindfulness decreased burnout and increased employee satisfaction, despite taxing job demands (Goodman \& Boss, 2002). Further, in a study of nurses and healthcare professionals, these researchers found that mindfulness decreased stress burnout and anxiety and increased empathy, focus, and mood. 
In a sample of 173 first-year students engaged in face-to-face teaching at universities, Merhi, Sánchez-Elvira-Paniagua, and Palací (2018) found that personal resources, including intrinsic motivation, academic persistence, high levels of wellbeing, and academic satisfaction, positively predicted academic engagement. On the other hand, the perception of academic demands, procrastination, negative affect, detrimental procrastination, and low levels of engagement and self-motivation predicted academic burnout. The same variables, except for engagement and intrinsic motivation, also predicted core burnout (Merhi, Sánchez-Elvira-Paniagua, \& Palací, 2018).

Korean students are under enormous pressure to achieve good grades in school. Noh, et al (2016) examined the effects of negative and positive religious coping on students' well-being. In a longitudinal study, 388 Korean middle school students reported their religion and their level of academic burnout. At a follow-up four months later, the researchers found that those who subscribed to a religious belief system had lower levels of burnout. These researchers utilized data from the National Statistical Office and found that $10 \%$ of Korean students had contemplated suicide, and $53 \%$ reported that this was primarily due to academic pressures. Interestingly, recent research has indicated that religious coping can have both positive and negative effects on psychological health. Noh et al. (2016) defined religious coping as "religious behaviors or cognitions that help a person cope with or adapt to difficult life situations or stress (p. 136).

Researchers have identified several strategies for coping with burnout. There are two major categories of coping strategies: problem-focused coping and emotion-focused coping (Demerouti, 2015). Demerouti (2015) suggested that problem-focused coping is positively correlated with burnout and emotion-focused coping is negatively correlated 
with burnout. To reduce the negative effects of work stressors, people use coping, recovery, and compensation strategies to change the stressors or the way they respond to stressors. Some people use job crafting to alter the characteristics of the job to make it less hindering and more motivating. Finally, some individuals create boundaries between work and nonwork domains (actively detaching from work) so that they experience fewer work-family and family-work conflicts (Demerouti, 2015).

Perfectionism also contributes to burnout (Fye, Gnilka, \& McLaulin, 2018). As part of their work, school counselors must address the academic, career, and emotional needs of students (Fye et al., 2018). Although counselors' training focuses primarily on mental health, they may engage in other duties at school, such as lunch and bus duty, serving as a testing coordinator, and substitute teaching (Fye et al., 2018).

According to Bidlan (2014), healthcare professionals have an increased risk for occupational stress and burnout because of the emotionally challenging and physically demanding nature of their jobs. These challenges may include conflicts with colleagues, improper service delivery to patients, absenteeism, high dropout rates, and poor teamwork.

Bidlan and Sihag (2014) examined employees with a positive orientation who have an optimal emotional tone on the job and depend on problem-focused coping, noting that this makes them less vulnerable to burnout. Interestingly, in this study, males scored higher than females on burnout (Bidlan \& Sihag, 2014).

The first and most central aspect of burnout is emotional exhaustion. Emotional exhaustion involves the depletion of emotional resources and feelings of being "empty" or "worn out" (Carmona, Buunk, Peiró, Rodríguez, \& Bravo, 2006, p. 85). The second 
aspect of burnout is depersonalization, which involves the negative or cynical perspective toward one's work or the people one cares for (Carmona et al., 2006). The third aspect of burnout is personal accomplishment, in which people view their accomplishments negatively. However, despite all the research on burnout, many researchers have neglected the social context of burnout (Carmona et al., 2006). These social contexts can include relationship with and the general esprit de corps of the work environment one's colleagues (Carmona et al., 2006). Researchers have linked the following to burnout in teachers: work-related factors, excessive time pressure, poor relationships with colleagues, large classes, lack of resources, fear of violence, students' behavioral problems, role ambiguity and role conflict, inadequate opportunities for promotion, lack of support, and lack of participation in decision-making (Carmona et al., 2006, p. 86). In their article "Do Social Comparison and Coping Styles Play a Role in the Development of Burnout? Cross-sectional and Longitudinal Findings," Carmona et al. (2006) found that direct and palliative coping styles were independent predictors of burnout: people who reported using a direct coping style tended to have lower levels of burnout, whereas those who reported using a palliative coping style tended to have increased burnout over time (Carmona et al., 2006).

Doolittle (2007) reported that, among parish-based clergy, spirituality level was positively correlated with personal accomplishment, emotional exhaustion, and depersonalization. Doolittle also noted that specific coping strategies—such as acceptance, active coping, planning, and positive reframing of problems - may prevent burnout. 
Sihag and Bidlan (2014) found high levels of occupational stress and burnout among healthcare professionals. They also noted that workers in human service organizations, such as nurses, police officers, social workers, and teachers, are more susceptible to burnout. Some healthcare organizations have begun to focus on preventing burnout as opposed to treating it (Sihag \& Bidlan, 2014).

There is also work suggesting that the use of coping strategies for burnout may differ across ethnic groups. Within the field of childcare, low wages and small benefits packages contribute to burnout (Evans, Bryant, Owens, \& Koukos, 2004). In their study, Evans et al. (2004) tested the efficacy of several coping strategies. Strategies in the problem-focused domain included active coping, planning, suppression of competing activities, restraint coping, and seeking instrumental support. Strategies in the emotionfocused domain included seeking emotional and social support, focusing on and venting emotions, positive reinterpretation through growth, and turning to religion as a source of comfort.

In Evans et al.'s (2004) sample, African American participants had lower levels of education and higher levels of poverty and unemployment than the Caucasian participants. They hypothesized that such differences in resources and socioeconomic status interact with psychological symptoms to increase psychological symptoms of distress.

In a study on the effects of religion on coping, Nooney and Woodrum (2002) found that the frequency of prayer was strongly and positively related to religious coping $(r=.54)$, and frequency of church attendance was moderately and positively related to church-based social support $(r=.23)$. Interestingly, the frequency of attendance was 
more strongly positively related to religious coping $(r=.41)$ than to social support $(r=$ .24). In a sample of older adults, Chen et al. (2007) found that "those attending religious activities on a weekly, monthly or occasional basis were significantly less likely to have suicidal ideation and emotional distress than those who never participated or participated on a less frequent basis." One study assessed the relationship between spiritual struggles and psychopathology symptoms in individuals who had not recently suffered from illness (McConnell et al., 2006). In this study, McConnell et al. (2006) differentiated between positive religious coping and negative religious coping:

Positive religious coping rests on a sense of spirituality, a secure relationship with God, a belief in life's meaning, and spiritual connectedness with others. Spiritual struggles are defined as efforts to conserve or transform a spirituality that has been threatened or harmed (p. 1470).

They found that spiritual struggles were positively associated with a wide range of psychopathology symptoms, including symptoms of anxiety, phobic anxiety, depression, paranoid ideation, obsessive-compulsiveness, and somatization. Furthermore, they found that "individuals dealing with an illness or injury may be especially susceptible to psychopathology associated with spiritual struggles" (McConnell et al., 2006). People who engage in negative religious coping have negative religious interpersonal relationships, reappraisals of God's powers, and negative attitudes toward their religious backgrounds. Schottenbauer et al. (2006) stated, "Studies have repeatedly shown that most Americans turn to religion in times of stress; in some populations, religious coping is employed as often as non-religious coping." According to Grosch and Olsen (2000),

Most clergies began their careers with lofty ideals, enormous optimism, idealism about their ability to be helpful, and a commitment to help people... The sad reality is that for many, idealism, commitment, and compassion gave way to disillusionment and despair. Contrary to their initial expectations, many of their well-intentioned 
ministerial efforts were both ineffective and unappreciated, leading to discouragement and, in some cases, burnout and despair. (p. 619). Is this a direct quote? If it is, include quotation marks and remove indentation.

The question is "What should clergy do?" Schottenbauer et al.'s (2006) found that there was not a large difference between religious coping and non-religious coping, but they also noted that "collectively, our results may guide the development of specific interventions for use with highly religious Christians who seek counseling to cope with a stressful situation" (p. 1190).

The need is especially great for counselors who wish to work with clergy. Many clergy members are not amenable to secular counseling, which may, in turn, prevent them from seeking out and receiving professional help. Counselors need to transition from having a set of solutions and tools to asking questions about and supporting the wisdom in the client's existing support system (Blanch, 2007). It is important for all professionals to cope with mental and general exhaustion and to maintain low levels of burnout. Humans have an innate ability to cope with changes and challenges in the world (Hoghwalder, 2009). In most jobs, people must train themselves on how best to cope with and overcome pressure (Hoghwalder, 2009). For instance, individuals working for stock market firms must plan their schedules, even before their recruitment. They must consider how to cope with jobs that involve high levels of both mental and general pressure, so that they can succeed; otherwise, they may succumb to the high attrition rate in the industry. To effectively cope with the mental and general pressures that lead to exhaustion and burnout, people must employ systematic techniques at both the individual and organizational levels. People need to develop strategies for working in high-pressure 
jobs without decreasing efficiency or work quality (Bakker, van der Zee, Lewig, \& Dollard, 2006). They can achieve this with various therapies, nutritious foods, drinks, and even exercises (Bakker et al., 2006), which can help them to easily overcome, or cope with, high-pressure situations that can increase stress levels.

\section{How Burnout Affects the Clergy}

Bradley (1969) wrote about staff burnout in an article about probation officers who were running a community-based program for juvenile delinquents (as cited in Schabracq, Winnubst, \& Cooper, 2003, p. 383). People originally believed that Freudenberger coined the term burnout to describe stress-related symptoms of emotional and physical exhaustion of persons working in alternative health care institutions (Schabracq et al., 2003); however, this belief is untrue. In a dissertation titled $A$ Study on Various Factors and Their Relationship to Burnout Among Seventh-Day Adventist Clergy, Demaray identified the following symptoms of burnout: general malaise; emotional, physical, and psychological fatigue; feelings of helplessness; hopelessness; and a lack of enthusiasm about work and life in general. He also noted that burnout is emotionally, physically, and spiritually observable. Physical symptoms can include fatigue, changes in weight, sleep disturbance, psychomotor agitation or retardation, headaches, gastric upset, changes in sex drive, and other hypochondriacal complaints. Emotional symptoms include apathy, obsessive thoughts, loss of creativity, paranoia, irritability, constant worrying, changes in humor, efforts to act as if everything is normal, loneliness, difficulty being playful, crying, the flight of ideas, trouble concentrating, and feelings of hopelessness (Edwards, 2003). 
Over the last decade, researchers have developed assessment tools for measuring spirituality, but there are several problems related to the variety of available instruments and of measured constructs. One issue is the conceptual redundancy among these new scales.

Golden, Piedmont, Ciarrocchi, and Rodgerson (2004) questioned the extent to which the scales measured unique constructs and the extent to which they merely reiterated a prevalent construct. If they are merely reiterating a familiar construct, the scales do nothing more than convert personality variables into religious ones.

Virginia (1998) investigated burnout and depression among Roman Catholic, secular, religious order, and monastic priests using the MBI. However, because of the variety of religions researchers study, it is not always possible to compare results across studies. For example, Virginia (1998) compared three different kinds of priests, but the only type of priest that researchers can compare to most other clergy is the secular priest. A great deal of the early research on burnout focused on situational or environmental factors at work. Golden et al.'s (2004) research suggests that there is a relationship between burnout and role conflict, role ambiguity, and role overload (Golden et al., 2004). Golden and colleagues (2004) also noted that after controlling for age and gender, role conflict explained the most significant percentage of variance in emotional exhaustion and depersonalization. Pretorius (1994) found that role conflict, and the number of students was significant predictors of emotional exhaustion among teachers, while several students and role ambiguity were significant predictors of depersonalization. 
Manlove (1994) explored the effects of role conflict and role ambiguity on burnout in childcare workers and found that both predicted significant amounts of the variance in burnout over demographic variables (age, marital status, and number of children living at home) and professional variables (wages, education level, hours worked, and years in the field). Golden et al. (2004) found significant negative correlations between burnout and spirituality. The demands of ministry can lead to symptoms of stress. Virginia (1998) found that "Roman Catholic secular clergy experienced greater emotional exhaustion than did monastic priests. Secular clergy also revealed a much greater degree of depression (72\%) than did both the religious and monastic clergy (40.8\% and 39.5\% respectively)" (p. 85). To explain the differences between priest groups, Virginia (1998) added: "Ministry for the secular priest is one of the multiple demands. Secular ministry places the parish priest on call at all hours of the day or night. Daily life tends to be one of flux, not the fixed routine, and at times can approach the chaotic. The religious order of priests, in comparison, has a daily schedule. Their day consists of prayer... and community activity...their life seeks a balance between active ministry, community life, and prayer." (p. 87).

Knox, Virginia, Thull, and Lombardo (2005) explained that life inside the monastic enclosure provides monastics with silence, a reflective environment, and a balanced rhythm between prayer and work. By comparison, there are three ways that clergy live out their lives, and they live them out in vastly different ways (Knox et al., 2005). One important step in assessing the resources available to clergy is determining the psychological effects of religion on clergy members. Most studies on the topic have 
found that highly religious people have better psychological health. In a study conducted in Canada, Baetz, Bowen, Jones, and Koru-Sengul (2006) found that frequency of worship was negatively correlated with chances of developing a psychiatric disorder. In contrast, people who considered higher spiritual values important (in a search for meaning, giving strength, and understanding life's difficulties) were more likely to develop a psychiatric disorder.

Research on the generic indicators of public religious behaviors and activities (e.g., attendance affiliation) has suggested that the increased social integration and support provided by institutionalized religion results in improved mental health (Nooney \& Woodrum, 2002). Pfeifer and Waelty (1999) found that religiosity was not associated with either extraversion or neuroticism. Glas (2007) found that "having some religious affiliation appears to be related to lower anxiety levels in the general population." He further noted:

"In a comprehensive review of the relation between religion and medicine, Koenig (2016) summarizes finding[s] in seven clinical trials and sixty-nine observational studies examining the religion-anxiety relationship. Almost half of these studies show lower levels of anxiety among more religious people; seventeen studies report no association; seven reports mixed or complex results, whereas ten studies suggest greater anxiety among those considering themselves to be more religious.” (p. 621)

\section{Statement of the Problem}

Some researchers have defined burnout as a prolonged response among those working in helping professions and/or experiencing chronic emotional stressors, and they consider burnout to be a combination of exhaustion, cynicism, and inefficacy (Doolittle, 2007). In recent work, researchers have proposed that there may be an interaction 
between personality and burnout. Most notably, researchers have hypothesized that there is an interaction between burnout and the five broad dimensions of personality, conceptualized in the five-factor model of personality (FFM; Bakker et al., 2006; Hurt, Grist, Malesky, \& McCord, 2013), and have noted that clergy members reported high levels of emotional exhaustion, feeling drained, and/or discouraged. In one study, clergy members who reported high satisfaction in their work described how ministry added purpose and meaning to their lives (Barnard \& Curry, 2012).

According to Grosch and Olsen (2000), as active members of a "helping profession," clergy often experience burnout, and burnout can result from the interplay between narcissism and perfectionism or from issues related to bureaucracy, poor administrative support, and challenging work conditions. Also, clergy members may have high intrinsic levels of idealism, optimism, and compassion (Miner, 2007). Miner (2007) indicated that burnout, anxiety, and depression could become "costly problems" for clergy, adding that it would be helpful to understand that personal factors can be predictive of anxiety, depression, and burnout (p. 18).

Given that organizational structures vary, there may be important differences between occupations within the clergy. Some religions, such as the Roman Catholic Church, have a top-down organizational structure (Zech \& Gautier, 2004). Clergy in such organizations may experience different problems than clergy in a bottom-up organizational structure. For example., in the United Pentecostal Church, which has a General Superintendent, a Board of Presbyters who found and develop churches, and two Assistant General Superintendents; International, 2013). 
Thus, variations in organizational structure may present different challenges to associated clergy members facing burnout. (join with previous paragraph)

\section{Purpose of the Study}

The purpose of this study was to examine the relationship between personality and burnout among protestant clergy in the United States.

While some researchers have conducted correlational studies to determine the relationship between burnout and personality, few have directly examined how the FFM applies to the clergy. In one notable study on clergy members' personality and burnout, Barnard and Curry (2012) suggested that four dimensions may predict clergy burnout. They proposed several reasons why clergy might experience burnout. First, they may experience burnout because of an excessive desire to please others. Second, a tendency toward guilt or shame might negatively predict satisfaction and positively predict emotional exhaustion. Third, emotional self-care (offering kindness, patience, and understanding of oneself) might be positively correlated with satisfaction and negatively correlated with emotional exhaustion. Finally, the inability of clergy members to not take their work home may be negatively associated with burnout (Barnard \& Curry, 2012). Further evidence of the relationship between burnout and personality comes from Lee's (2010) finding that teaching clergy members how to maintain adequate social and emotional boundaries and helping them foster a "grateful disposition" may aid in the adjustment of the clergy to the stressors that lead to burnout (Lee, 2010). Miner (2007) suggested that, in the early years of ministry, neuroticism predicts emotional exhaustion, 
depression, and anxiety; extraversion predicts personal accomplishment; and openness to change predicts emotional exhaustion and depersonalization.

\section{Research Questions}

The following questions guided this research:

- Research Question 1: Is there a significant canonical correlation between burnout and personality traits?

- Research Question 2: Do the FFM personality variables predict depersonalization?

- Research Question 3: Do the FFM personality variables predict emotional exhaustion?

- Research Question 4: Do the FFM personality variables predict personal accomplishment?

\section{Conceptual Framework}

Several researchers have suggested that emotional exhaustion is positively correlated with neuroticism. In The Handbook of Work and Health Psychology, (date) the authors suggested that emotional exhaustion is also positively correlated with openness. However, they also hypothesized that emotional exhaustion is negatively correlated with extraversion (Morgan \& de Bruin, 2010; Schabracq et al., 2003) and that depersonalization is positively associated with neuroticism and negatively associated with agreeableness (Schabracq et al., 2003). Schabracq et al. (2003) also hypothesized 
that personal accomplishment is negatively correlated with neuroticism, extraversion, and openness but positively correlated with conscientiousness. Other research has suggested that there are correlations between the burnout factors, but not all of these correlations may be significant. Thus, in the present study, I focused on the factors that correlate with mental and physical exhaustion in addition to burnout. With this study, I aimed to identify potential reasons for burnout in the United States and elsewhere, particularly for individuals working in specialized professions like nursing and the ministry.

Kokkinos (2007) asked a representative sample of 447 primary school teachers to complete measures of burnout, personality, and job stressors and provide demographic and professional data. Results showed that neuroticism predicted all dimensions of burnout, including negatively predicting personal accomplishment (Kokkinos, 2007).

Kokkinos (2007) found that neuroticism predisposed people to experience adverse life events, whereas extraversion caused people to engage in activities that are "cheerful, optimistic and energetic" and that help them overcome stressful conditions (p. 231).

Kokkinos (2007) found that employees who scored higher in negative affect (neuroticism) reported higher levels of emotional exhaustion. Those who scored high in agreeableness were more nurturing, sensitive, humanistic, and were less likely to dehumanize others. In a meta-analysis of more than 250 studies on burnout, Kokkinos (2007) reported that neuroticism was "one of the most forceful personality correlates of burnout, particularly of emotional exhaustion."

Bakker et al. (2006) studied burnout in a sample of 80 volunteer counselors who cared for terminally ill patients. They measured burnout using the MBI. The results of three stepwise multiple regression analyses indicated that emotional exhaustion was 
uniquely predicted by emotional stability; depersonalization is predicted by emotional stability, extraversion, and intellect/autonomy; and personal accomplishment is predicted by extraversion and emotional stability (Bakker et al., 2006). Bakker et al.'s (2006) sample included 75 female volunteers and five male volunteers, with a mean age of 54 years. Bakker et al.'s (2006) results were as follows:

- Neuroticism was the sole predictor of emotional exhaustion.

- Three personality factors accounted for $17 \%$ of the variance in depersonalization, which was significant, $F(5,75)=5.21, p<.01$ : neuroticism $(\beta=0.32, p<0.01)$, extraversion $(\beta=-0.23, p<.01)$, and autonomy $(\beta=-0.22, p<.05)$. All three factors significant affected depersonalization. This meant that the volunteer counselors had more negative attitudes toward their patients when they were less emotionally stable, more introverted, and less autonomous.

- Both extraversion $(\beta=.41, p<.001)$ and neuroticism $(\beta=-0.26, p<.05)$ were significant, independent predictors of personal accomplishment. This study among counselors (human service workers) is very similar to the present study; and justifies my utilization of the FFM as a predictor measure of burnout.

\section{Significance of the Study}

Given that more than $50 \%$ of clergy members consider leaving the ministry (Bardiau-Huys, 2014), the present study on burnout in this population is important. Moreover, attendance is declining in more than $90 \%$ of churches in the United States 
(London \& Wiseman, 2011). Clergy members' reasons for leaving the ministry include inadequate training, lack of mentorship, and unrealistic expectations of congregants.

These statistics are startling and point to the need for improved ministry preparation and support. This research also generated quantitative and qualitative data regarding the relationship between stress and burnout in clergy members in the United States. Identifying the causes of stress and burnout and the specific personality factors that relate to burnout may empower clergy members.

Scott and Lovell (2015) conducted an 18-month study, collecting data on 51 rural clergy members with the intent of helping them to overcome some of the biggest problems of their professional lives: loneliness, isolation, burnout, the imbalance between personal and professional life, and the absence of self-care. According to the authors, "Researchers have long identified burnout as a considerable risk factor associated with the field of social work. Furthermore, [it has been found that] clergy members' mean scores on the MBI closely resemble those of secular human service professionals" (Scott \& Lovell, 2015, p. 73).

Many new clergies enter congregations with lofty ideals of helping others, growing their membership, and being a resource in the community; however, they later find these grand expectations to be taxing on their physical health, emotional resources, and even their family systems.

The MBI can be a useful measure of self-care. For example, MBI scores may reveal whether a parent organization provides enough resources to allow clergy to take vacations and/or rejuvenate themselves. Without a standard measure of burnout, these variables would be difficult to assess. The MBI may provide valuable information to 
both clergy members and their parent organization, allowing the organization to effectively support clergy. A pastor experiencing burnout is a less effective caretaker. Knowing how personality factors predict burnout among protestant clergy members can lead to an increase in their overall effectiveness and their self-care and service to others.

\section{Definition of Terms}

Stress refers to physical and mental strain (Randall, 2013). When stress lasts for an extended period, it becomes burnout (Montero-Marín et al., 2013).

Burnout involves the length of time a person has been in a particular job; their expectations when starting the job; whether these expectations are met; and the levels of emotional exhaustion, depersonalization, and accomplishment that a person experiences in the job (Gascon et al., 2013). People often confuse burnout with stress, but the latter is a situational variable involving more immediate expectations and efficacy and excluding the "time-length perspective" (Montero-Marín \& García-Campayo, 2010).

Emotional exhaustion is the state of depleted energy from excessive physiological and emotional demands (Wanwen, Xiaoyan, Arnulf, \& Meijuan, 2014).

Depersonalization involves the development of cynical attitudes, as well as detached feelings toward patients or others (R. T. Lee, Seo, Hladkyj, Lovell, \& Schwartzmann, 2013).

Personal accomplishment refers to one's self-evaluation and the level of satisfaction with one's work accomplishments (Morgan, de Bruin, \& de Bruin, 2014). 
Neuroticism refers to one's level of adjustment or maladjustment (McCrae \& Costa, 2010).

Extraversion is the extent to which one is sociable (e.g., prefers large groups and gatherings). Extraverts are assertive, active, and talkative (McCrae \& Costa, 2010). Agreeableness encompasses behavioral characteristics that others see as kind, sympathetic, cooperative, warm, and considerate (Thompson, 2008).

Openness includes six dimensions: active imagination or fantasy, aesthetic sensitivity, attentiveness to inner feelings, preference for variety, and intellectual curiosity (Costa \& McCrae, 1992).

Conscientiousness is one's ability to control impulses and manage desires. A conscientious individual is purposeful, strong-willed, and determined (McCrae \& Costa, 2010).

\section{Organization of the Study}

Chapter 1 focuses on the background of the study; the statement of the problem; the purpose of the study; the significance of the study; research questions; definitions of terms; the conceptual framework, and delimitations and limitations of the study.

Chapter 2 explains the relationship between burnout and stress. Issues related to measuring burnout in clergy members; correlates of burnout, mental health, and religion; and implications were investigated. Existing literature, including original research in academic journals, were summarized and analyzed. 
Chapter 3 focuses on the participant sample and recruitment methods, as well as the research model (correlational), variables, research instruments, and hypotheses.

Chapter 4 provides details on the research findings and data analyses.

Chapter 5 addresses the results, discussion, and conclusions of the research, and suggested recommendations for future research and practice. 


\section{CHAPTER 2}

\section{REVIEW OF THE LITERATURE}

The purpose of this literature review is to examine the body of research on burnout experienced by the Protestant clergy in the United States. A brief overview on the phenomenon is presented, followed by an account of burnout patterns by occupation; continued by a discussion of research associated with the burnout factors, and an analysis and summary of the dissertation.

Researchers have widely accepted that burnout occurs because of chronic job stress. For example, demanding jobs may generate an emotional exhaustion response. People may have high levels of emotional exhaustion because their jobs require a high level of contact with other people. To cope with these stressors, clergy tend to withdraw themselves from such extensive contact with others (Taris, Le Blanc, Schaufeli, \& Schreurs, 2005). Although this withdrawal may help a person to cope with job demands, excessive detachment, coupled with a lack of concern by overseers, may cause staff to respond in "negative, callous, dehumanized, and depersonalized ways" (Taris et al., 2005, p. 240).

Further, as depersonalization persists, feelings of disenfranchisement may increase. The results is a downward spiral from emotional exhaustion to depersonalization and finally to low levels of personal accomplishment (Taris et al., 2005). Thus, Depersonalization can be detrimental to persons dealing with high-level care patients, because it can result in a lack of serious concern for the care and feelings of patients by professional staff who are expected to dedicate their energy to coping with 
and adapting to the high stress levels associated with their job. Hence, depersonalization results in decreased service delivery efficiency, which could lead to patients developing health complications because of a lack of professional attention. This can result in an increased financial burden to parishioners and a deterioration of their spiritual well-being.

\section{Brief Overview of Burnout}

As early as the late 1960s, Bradley (1969) wrote about staff burnout in an article about probation officers who were running a community-based program for juvenile delinquents (as cited in Schabracq, Winnubst, \& Cooper, 2003, p. 383). is believed to be . In a dissertation titled $A$ Study on Various Factors and Their Relationship to Burnout Among Seventh-Day Adventist Clergy, Edwards (2003) cited Demaray's description of burnout as being “... accompanied by an array of symptoms that include a general malaise; emotional, physical, and psychological fatigue; and feelings of helplessness, hopelessness, and a lack of enthusiasm about work and even about life in general" (p. 12). He further stated,

there are three major areas that are associated with the burnout syndrome. These are symptoms that are physically, emotionally, and spiritually observable. The physical symptoms include complaints of fatigue, weight loss or weight gain, sleep disturbances, psychomotor agitation or retardation, frequent headaches, gastric upset, changes in sexual drive, and hypochondriacal complaints. The emotional symptoms include apathy, obsessive thought patterns, loss of creativity, paranoia, irritability, constant worrying, loss of humor or development of dark humor, sporadic efforts to act as if everything is back to normal, complaints of loneliness, inability to be playful or become interested in diversionary activities, excessive crying, flight of ideas, trouble concentrating and feelings of hopelessness. (Edwards, 2003)

Over the last decade, researchers have developed assessment tools for measuring spirituality, such as the Spiritual Well-Being Scale (You \& Yoo, 2016). However, there are several problems related to the variety of available instruments the constructs 
measured. One issue is the conceptual redundancy among these new scales. Golden et al.

(2014) asked

to what extent do these scales measure unique constructs in the individual, and to what extent are they the reiteration of a universal construct? The second concern whether the spiritual constructs measured are simply the "religification" of existing personality variables?

Virginia (1998) investigated burnout and depression among Roman Catholic, secular, religious order, and monastic priests using the MBI. However, because of the variety of religious measures utilized, it was not always possible to compare results fruitfully across studies. For example, Virginia (1998) compared findings on three different kinds of priests, but found that only findings on secular priests showed consistency.

Golden et al. (2004) noted that "much of the early burnout research focused on situational or environmental factors at work. Evidence exists for a relationship between role conflict, role ambiguity, and role overload and burnout." They further stated, After controlling for age and gender, role conflict explained the most significant percentage of variance in emotional exhaustion and Depersonalization. Pretorius (1994) found that role conflict, and the number of students was significant predictors of emotional exhaustion among teachers, while the number of students and role ambiguity were significant predictors of Depersonalization.

Manlove (1994) explored the effects of role conflict and role ambiguity on burnout in childcare workers and found that both predicted significant amounts of the variance in burnout across the demographic variables of age, marital status, and number of children living at home) on one hand and others variables such as (wages, education level, hours worked, and years in the field). Golden et al. (2004) found significant negative correlations between burnout and spirituality. The demands of ministry can lead 
to symptoms of stress. Virginia (1998) found that "Roman Catholic secular clergy experienced greater emotional exhaustion than did monastic priests. Secular clergy also revealed a much greater degree of depression ( $72 \%)$ than did both the religious and monastic clergy ( $40.8 \%$ and $39.5 \%$ respectively)" (p. 85).

To explain the differences between priest groups, Virginia (1998) added:

Ministry for the secular priest is one of multiple demands. Secular ministry places the parish priest on call at all hours of the day or night. Daily life tends to be one of flux, not the fixed routine, and at times can approach the chaotic. The religious order of priests, in comparison, has a daily schedule. Their day consists of prayer...and community activity...their life seeks a balance between active ministry, community life, and prayer. (p. 87)

Knox, Virginia, Thull, and Lombardo (2005) explained that life inside the monastic enclosure provides monastics with silence, a reflective environment, and a balanced rhythm between prayer and work. By comparison, there are three ways that clergy live out their lives, and they live them out in vastly different ways (Knox et al., 2005).

One important step in assessing the resources available to clergy is determining the psychological effects of religion on clergy members. Most studies on the topic have found that highly religious people have better psychological health. In a study conducted in Canada, et al (2006) found that frequency of worship was negatively correlated with chances of developing a psychiatric disorder. In contrast, people who considered higher spiritual values important (in a search for meaning, giving strength, and understanding life's difficulties) were more likely to develop a psychiatric disorder. 
Pfeifer and Waelty (1999) found that religiosity was not associated with either extraversion or neuroticism. Glass (2007) found that "having some religious affiliation appears to be related to lower anxiety levels in the general population." He further wrote,

In a comprehensive review of the relation between religion and medicine, Koenig (2016) summarizes finding[s] in seven clinical trials and sixty-nine observational studies examining the religion-anxiety relationship. Almost half of these studies show lower levels of anxiety among more religious people; seventeen studies report no association; seven reports mixed or complex results, whereas ten studies suggest greater anxiety among those considering themselves to be more religious. (p. 621)

Nooney and Woodrum (2002) reported that "studies using generic indicators of public religious behaviors and activities (e.g., attendance affiliation) explain their positive relationship with mental health as a result of the increased social integration and support that institutionalized religion provides."

Theoretical Overview of Occupational Type and Burnout

Golebiewsky and colleagues presented an alternative theory on the development of burnout. They called this the phase model (Taris et al., 2005). In this model, Golebiewsky et al. (1988) separated each of the MBI dimensions into low and high levels, creating eight phases that individuals may pass through to their way to burnout.

The eight-phase model of burnout begins with individuals with low burnout and culminates in phase eight with high burnout. This model describes how some people experience a stressor regardless of frequency or intensity (Goodman \& Boss, 2002).

The conservation of resources theory focuses on occupational burnout. Researchers have tested this theory by conducting a study in Nigeria, using measures of emotional intelligence, self-efficacy, organization-based self-esteem, optimism, and 
burnout. In Nigeria, paramilitary personnel provide services which include the "regulation of people and goods in and out of the country, border and immigrant control, issuing travel documents, correctional duties, disaster management, control of civil agitations, combating petroleum pipeline vandalism, and policing the nation's borders" (Ojedokun \& Idemudia, 2014, p. 107). These responsibilities often result in high stress levels due to understaffing, work overload, inadequate infrastructure, and poor and delayed salaries. Such high levels of stress may lead to burnout and a general lack of efficiency.

There are several other models of burnout. For example, Gascon et al. (2013) suggested that the prevalence of aggression toward healthcare providers may predict burnout among doctors and nursing professionals. Leiter and Maslach (2013) presented a double process model of burnout, which included exhaustion and overload as well as personal and value conflicts.

Gascon et al. (2013) found that $11 \%$ of health care professionals have been physically assaulted at least once, over $34 \%$ have experienced threats on at least one occasion, and over $36 \%$ have been subject to insults. Overall, there was evidence that not only did excess workload predict burnout but so did interpersonal conflict and mismatched values. Ahola (2006) suggested that burnout peaks for women after about 17 years on the job. Some researchers have suggested that burnout is most noticeable after 11 years in the same job. However, there is a lack of empirical evidence for this claim. Moreover, this pattern of results was more prevalent in health care professions than in other professions (Gascon et al., 2013). A number of studies in the United States and in other countries have found that the ratio of patients to healthcare staff is extremely high. 
A similar pattern is emerging for psychiatrists, as there are many psychiatric patients in nursing homes who require specialized care but not enough psychiatrists to adequately care for them.

Although physicians try to attend to all patients within a certain timeframe, this is not always possible. Physicians struggle to manage tight timelines and duty schedules and to attend to their many patients; this leads to mental and physical exhaustion, finally resulting in burnout.

Most healthcare facilities have an overworked staff who must overexert themselves to deliver the best services. There is a growing concern over a shortage in healthcare providers; for existing staff, this shortage has resulted in excessive workloads and extreme levels of mental and physical exhaustion leading to burnout.

The military is another profession that has a high rate of burnout, which may result in unsatisfactory job performance and a higher rate of job turnover. Researchers have suggested that beliefs about health may influence job burnout (Vinokur, Pierce, \& Lewandowski-Romps, 2009), and burnout may be linked to depression and insomnia. Researchers at the University of Michigan found that job burnout correlated with working conditions that change over time (Vinokur et al., 2009). Researchers have also linked lack of sleep to burnout. In a recent study of 1,384 nurses in 39 hospitals, Weishan, et al (2015) found that 169 nurses slept fewer than 6 hours a day and the remaining participants slept seven or more hours per day. Nurses who slept fewer than six hours had a higher risk of job strain. The researchers conducted a generalized additive model analysis and found a linear relationship between sleep duration, job strain, and clientrelated burnout (Weishan et al., 2015). 
Individuals working in banking are also prone to burnout. In a study of 1,341 banking professionals, results show $56 \%$ of the participants had a higher risk of burnout across two dimensions of the MBI - General Survey. Amigo, Asensio, Menéndez, Redondo, and Ledesma (2014) suggested that burnout may be prevalent in this industry because it involves constant and direct contact with people-especially in the role of helper (Amigo, Asensio, Menéndez, Redondo, \& Ledesma, 2014).

Workers in the banking industry often arrive at work early and stay at work late. Clients in banking institutions expect satisfactory, speedy service, but bank staff must scrutinize all documents before delivering expected services because cash services are extraordinarily fragile and risky. Their duties, coupled with excessive demands by some clients, can result in demoralization among staff, the exhaustion of mental and physical energy reserves, and increased incidences of burnout. Decreases in job satisfaction may lead to burnout, low levels of efficiency and personal accomplishment, and potentially increases in financial losses or successful forgeries.

\section{An Exploration of the Research Between Personality and Burnout}

There is evidence suggesting a strong link between personality and burnout. Some researchers have suggested that the Big Five personality traits (openness, conscientiousness, extraversion, agreeableness, and neuroticism) directly correspond with the MBI constructs of burnout (emotional exhaustion, depersonalization, and personal accomplishment)( Morgan \& de Bruin, 2010; Schabracq et al., 2003). In The Handbook of Work and Health Psychology (Schabracq et al., 2003), the authors suggested that 
emotional exhaustion is positively correlated with neuroticism and openness, whereas depersonalization is positively correlated positively with neuroticism and negatively correlated with agreeableness. Lack of personal accomplishment is positively correlated to neuroticism, extraversion, and openness, and negatively related to conscientiousness.

In their meta-analysis of studies on burnout, Alarcon, Eschleman, and Bowling (2009) linked several personality variables to burnout. These variables included selfesteem, self-efficacy, locus of control, emotional stability, extraversion, conscientiousness, agreeableness, positive affectivity, negative affectivity, optimism, proactive personality, and hardiness.

Bakker et al. (2006) explored the connection between personality traits and burnout among Dutch volunteer counselors and found that only neuroticism significantly predicted emotional exhaustion. However, more recent research has suggested that there may be a stronger connection between personality and burnout.

Morgan and de Bruin (2010) found that neuroticism was positively correlated with both emotional exhaustion and cynicism and negatively correlated with professional efficacy. In addition, extraversion was negatively correlated with emotional exhaustion and cynicism and positively correlated with professional efficacy. Openness to experience was positively correlated with professional efficacy, and agreeableness was negatively correlated with cynicism and positively correlated with professional efficacy. Conscientiousness was negatively correlated with emotional exhaustion and cynicism and positively correlated with professional efficacy.

Hurt et al. (2013) conducted another study examining the relationships between the same personality traits and burnout (using the MBI). They found several significant 
correlations between neuroticism and all three MBI scales of burnout. Extraversion and conscientiousness were negatively correlated with professional efficacy, whereas agreeableness was positively correlated with it.

In another study, Hoghwalder (2009) investigated the relationships between the personality variables of neuroticism, extraversion, and conscientiousness and the burnout variables of emotional exhaustion, depersonalization, and personal accomplishment. Interestingly, participants who scored low on neuroticism also scored low on emotional exhaustion, and those who scored high on neuroticism also scored high on emotional exhaustion. The author noted, "Finally, it can be seen that Neuroticism may generally be considered as a vulnerability factor and extraversion and conscientiousness as protective factors for burnout" (Hoghwalder, 2009). These personality factors help in the process of safeguarding against burnout, while improving efficiency and increasing output. Neuroticism may directly contribute to depersonalization and lead to decreased efficiency in service delivery. Other factors, such as extraversion and conscientiousness, can help individuals to achieve success at both the personal and organizational levels.

\section{A Summary and Analysis of the Internal} Structure of the MBI

The relationship between personality and burnout cuts across three different dimensions - depersonalization, emotional exhaustion, and personal accomplishment. Researchers have found significant correlations between psycho-emotional variables (such as emotional stability, positive affectivity, self-esteem, and negative affect) and burnout (including its individual dimensions). There is a robust and consistent relationship between burnout and personality trait (Morgan et al., 2014). Examining 
different perspectives on the relationship between burnout and personality trait allows for a better understanding of the two variables.

In her theory on burnout, Maslach attempted to identify "lead factors" that helped individuals to counter, control, or cope with mental exhaustion or burnout, as well as factors that contribute to increased levels of burnout across professions. In recent years, several researchers have linked personality to burnout, including Kokkinos (2007), Joseph et al. (2011), and Bakker et al. (2006).

The MBI is an accredited research tool that researchers have used to conduct studies on factors such as depersonalization and emotional exhaustion (Schabracq et al., 2003). Researchers have used the MBI to measure burnout in various people-centered professions, such as nursing, banking, and the military. The MBI is an accredited tool, and many professionals have used it to help them reach peak performance levels. More importantly, appropriate use of the MBI may facilitate the increase of people's ability to rediscover and reinvent themselves, and so to improve their productivity and job success. Researchers have used the MBI to categorize individuals and to help them understand their innate strengths and to improve their services. Improved levels of efficiency and productivity lead to increased organizational output. Researchers have tested Maslach's theory of burnout with studies in the United States and in other countries and have added empirical support for the theory (Schabracq et al., 2003).

The Emotional Exhaustion Dimension of the Maslach Burnout Inventory

On the MBI, the emotional exhaustion scale is associated with two factors: the general exhaustion group factor and a general burnout factor (Morgan et al., 2014). 
Additionally, emotional exhaustion refers to feelings of emotional overextension and of being drained by contact with others (Dietzel \& Coursey, 1998). Emotional exhaustion can lead to general exhaustion, in addition to burnout, which leads to reduced work rates and levels of success (Vinokur et al., 2009). This exhaustion has a strong effect on work rates and efficiency levels for workers in various professions. This means that there is a pressing need for organizations and individuals to develop, train, and support mechanisms that will provide employees with a mental reprieve during each workday (Bakker et al., 2006). Mental relaxation can help people to reduce the amount of mental pressure that can lead to mental exhaustion, general exhaustion, and burnout. Here, burnout refers to the situation in which individuals' resourcefulness declines and their need for the appropriate intervention to restore it. Emotional exhaustion is a risk in many jobs, especially service-delivery related typed. Thus, clergy who provide counseling services may experience emotional and mental exhaustion. Such duties require concentration and wisdom to adequately and professionally serve the congregation and others. When there is a shortage of professional clergy, existing clergy members must double their efforts to meet their professional obligations. This increases their emotional exhaustion and leads to burnout. Burnout results in decreased output levels. Hence, organizations should adopt efficient operational systems to ensure that lower the chances for employees to become burnout and thus operate at peak performance levels (Bakker et al., 2006). This will improve employee motivation, increase efficiency levels, and reduce the effects of burnout in staff. 


\section{The Five-Factor Model and Its Relationship to Emotional Exhaustion}

On the MBI, the personal efficacy scale is negatively correlated with both the emotional exhaustion scale and the cynicism scale (Morgan et al., 2014), indicating that individuals have low productivity levels when they experience burnout.. Emotional exhaustion results from a poor work environment and/or ineffective operational systems, which can be due to a number of factors, such as multiple job responsibilities, increased work hours, and the lack of leisure time (Hoghwalder, 2009). Lack of leisure, coupled with long work hours, results in emotional exhaustion, significantly reduced efficiency, and elevated levels of burnout. Excessive responsibilities can lead to overworking and increased exhaustion, mental pressure, and mental exhaustion, resulting in decreased efficiency (Bakker et al., 2006). The main reason that employees have excessive job obligations is inadequate staffing (Bakker et al., 2006). Staffing is essential to efficiency and output. When staff only have one set of specific skills, they can only conduct job responsibilities in those areas. This leads to mental pressure and overworking, as well as reduced efficiency (Bakker et al., 2006). Prolonged levels of low efficiency due to burnout could result in unfair employee firings, the overworking of staff, and even the collapse of entire industries.

It is important that organizations regard their employees as their most essential and critical resource and invest in employee well-being. Such efforts can only increase personal and departmental efficiency (Hoghwalder, 2009). These investments may include the implementation of scheduling that encourages peak performance and of programs to increase staff motivation, hiring high-caliber staff in sufficient numbers, 
increasing focus on efficient working systems and conditions, and addressing any other factors that lead to reduced mental, physical, or overall exhaustion (Hoghwalder, 2009).

Researchers have found that personal accomplishment may mitigate the effects of burnout. According to Maslach, Schaufeli, and Leiter (2001), "the Personal Accomplishment subscale assesses feelings of competence and achievement in one's work with people" (p. 4). Other researchers have found that professionals with higher clinical workloads have higher levels of stress but also exhibit greater feelings of personal accomplishment (Deary et al., 1996). There is also evidence that two personality factors from the FFM, extraversion and conscientiousness, contribute to positive feelings of personal accomplishment (Deary et al., 1996; Kokkinos, 2007). Moreover, Kokkinos (2007) found that the Maslach burnout dimension of personal accomplishment was positively related to conscientiousness, extraversion, and openness and negatively related to neuroticism.

\section{The Five-Factor Model And Its Relationship to Depersonalization}

The second phase of professional burnout is depersonalization (Sylwia, Maciej, \& Maria, 2018). Individuals progress to this second phase after a prolonged period of emotional exhaustion, according to these authors. They noted that while it may protect individuals from the overwhelming demands placed on their mental and emotional resources depersonalization involves indifference and a lack of concern for clients affairs, as well as dehumanization, labeling, and lack of fair and effective treatment of them. Referring specifically to teachers, Sylwia et al. (2018), suggest that if teachers continue to experience emotional exhaustion and depersonalization, they will develop increased 
chronic somatic symptoms. These symptoms may manifest as a disease, such as an ulcer or hypertension. Mentally, they may suffer from depression, a sense of loneliness, and isolation from other others (Sylwia et al., 2018).

Existing research has found a positive relationship between neuroticism and both emotional exhaustion and depersonalization (Bakker et al., 2006; Kokkinos, 2007). Miner (2007) also found that extraversion was negatively correlated with depersonalization (Miner, 2007). In addition, there may be a negative relationship between openness to experience and depersonalization (Kokkinos, 2007). Kokkinos (2007) found a negative relationship between conscientiousness and depersonalization. Researchers have also found a negative correlation between depersonalization (as measured by the MBI) and the NEO factors of extraversion, agreeableness, and conscientiousness ( $r$ 's $=-.23,-.030$, and -.19 , respectively). Depersonalization was also positively correlated with neuroticism, $r=.35$ (Rodgerson \& Piedmont, 1998).

The Five-Factor Model and Its Relationship to Coping Roesch, Wee, and Vaughn (2006) found statistically significant relationships between the Big Five personality traits and coping. Neuroticism was positively correlated with emotionally-focused coping (emotional support). Extraversion, conscientiousness, and openness were positively associated with indices of problemfocused coping. Agreeableness was positively associated with active coping and humor. A meta-analysis of personality and coping suggests that personality has a weak correlation with general coping. Extraversion and conscientiousness (but not 
neuroticism) predicted problem-solving and cognitive restructuring (Connor-Smith \& Flachsbart, 2007).

The Depersonalization Dimension of the MBI

For some helping professions, researchers have defined burnout to be "a negative, indifferent or overly detached attitude to patients" (Pisanti, Lombardo, Lucidi, Violani, \& Lazzari, 2013, p. 698). Join with next para. Doolittle (2007) operationally defined depersonalization as "treating others as objects." One item on the MBI that measures depersonalization concerns clergy viewing parishioners as "impersonal objects" (Hills, Francis, \& Rutledge, 2004, p. 33). Today, clergy can bring work home with them on their tablets or computers. Technology has allowed people to immerse themselves in work while avoiding personal interaction; however, such interaction is vital to emotional health. Technology can allow people to escape from relationships.

Depersonalization affects not only healthcare professionals but also other professionals, like the military officers and banking officers, who have demanding job schedules. These jobs come with many responsibilities but little to no motivation. The jobs sometimes require great amounts energy, leading to both mental and physical exhaustion. Work at banks and by military personnel demands concentration and strong commitment, and these professionals may have difficulty finding time in their busy schedules to rest (Doolittle, 2007).

Military officers in a fighting operation must always remain alert and wary of any imminent attack. A lack of attentiveness can be disastrous, and duty calls for officers to be hypervigilant. This implies that they must spend their energy on activities to reduce 
stress levels in the body. If officers do not adequately monitor their stress levels, they may experience depersonalization, leading to concerns about how to regain mental and physical fitness and stability while avoiding low levels of personal accomplishments and substandard job delivery.

\section{Strengths of the Five-Factor Model}

Even though researchers have used the FFM over the past two decades, it is still useful. For example, Trull (2012) found that personality disorders can predict the personality facets of the FFM. Most personality disorders have a significant positive correlation with neuroticism and significant negative correlations with extraversion, agreeableness, and conscientiousness (Trull, 2012).

The creators of the FFM contended that theory can be applied cross-culturally, and research has generated support for this claim. In one study, researchers found evidence of these factors in more than 50 countries (Schultz, 2015), and a second study found consistency between personality traits in 22 countries (Mac Giolla \& Kajonius, 2017).

Another strength of the model is that it allows for the easy creation of personality profiles. To discover their personality profile, all people need to do is fill out a questionnaire. A principal strength of the FFM is its empirical foundation (Widiger \& Trull, 1997).

Interestingly, people are relatively stable over time for all five traits (Schultz, 2015). Results from research on American men and women from late adolescence into 
adulthood indicated that extraversion and neuroticism were stable factors (Schultz, 2015). A study comparing American and Belgian participants also found that extraversion, agreeableness, and conscientious remained stable over time, whereas openness increased during a period of four years (Schultz, 2015). In a longitudinal study, researchers found that participants who scored high on extraversion when they were students also scored high on extraversion 20 years later (Schultz, 2015) Over a 40-year period, extraversion and conscientiousness were the most stable personality factors (Schultz, 2015).

In a study of 271 teachers, researchers found that four of the five personality traits (neuroticism, extraversion, agreeableness, and conscientiousness) were correlated with burnout and that they were significant predictors for all dimensions of burnout (Sylwia et al., 2018). According to Sylwia and colleagues (2018), emotional exhaustion is a warning sign, in which teachers show an unwillingness and reduced interest in performing professional duties. Teachers experiencing emotional exhaustion can suffer from mental and somatic symptoms, such as a decline in activity, feelings of boredom, irritability, the persistence of tension, constant fatigue, gastrointestinal disorders, and headaches (Sylwia et al., 2018).

The FFM is useful because it is a taxonomy of universal traits (Bagby, Gralnick, Al-Dajani, \& Uliaszek, 2016). Other models of personality reflect the same five factors at different levels of personality (Bagby et al., 2016). There has been more literature on treatments using the FFM than any other model of personality (Bagby et al., 2016).

According to Bagby et al. (2016), one of the significant strengths of the FFM is that it is easy to study. Support for the validity of the FFM comes from research linking the five facets of personality with neuroanatomical differences. For example, Riccelli,et 
al(2017) found that neuroticism was associated with a thicker cortex and smaller area and folding in the prefrontal and temporal regions. Extraversion was associated with a thicker precuneus and smaller temporal cortex area, whereas openness was associated with a thinner cortex and more significant folding in the prefrontal and parietal regions. They also found that agreeableness was associated with a thinner prefrontal cortex and a smaller fusiform gyrus and that conscientiousness was associated with a thicker cortex and a smaller area and folding in prefrontal regions. These associations between brain structure and personality are important because they may allow researchers to identify brain maturational effects that can predispose or protect against psychiatric disorders (Riccelli et al., 2017).

Because the FFM allows for the easy study of personality, it is possible to use it to understand psychopathy from a "trait perspective" (Lynam \& Miller, 2015).

\section{Weaknesses of the Five-Factor Model}

One weakness of the FFM is that people can easily distort the results of FFM surveys (Schultz, 2015). Another criticism of the FFM is that it does not provide a model for how personality factors develop (Widiger \& Trull, 1997). Although science does not require consensus, it is important to note that there is not unanimous support for the FFM in the psychological community (Widiger \& Trull, 1997).

Some theorists have suggested that the FFM could be used in place of personality disorders. However, the creators of the FFM developed it using a "lexical approach," in which they defined the dimensions of personality using the words that people used to describe themselves. The problem with this approach is that, after the McCrae and Costa 
conducted the factor analysis and identified the five factors, the factors had convergent validity but not construct validity (Davis \& Millon, 1993). Therefore, the constructs that psychologists had historically used to describe personality disorders may no longer be validjoin with the next paraRecent research on the FFM has found that short questionnaires can provide an accurate measure of personality; for example, the NEO PI$\mathrm{R}$ has 240 items, and the NEO-FFI has 60 items (Nieto et al., 2017).

Although some researchers have suggested that the same five factors are stable across all individuals, there is also evidence suggesting that this is not true. Bowler, Bowler, and Cope (2012) argued that it is not possible to separate the measure of personality from the vagaries of human perception. According to Bowler et al., the FFM may not be accurate dimensions of personality, but more a reflection of perceived personality. They noted that "cognitive [c]omplexity is a measure of an individual's ability to incorporate and differentiate multiple environmental elements" (Bowler et al., 2012); the FFM does not account for this complexity.

\section{Using the Five-Factor Model of Assessment}

Because the creators of the FFM developed the model from a factor analysis of personality traits, the model lends itself well to empirical testing. Over the years, researchers have created several tools to the five personality variables of neuroticism, extraversion, openness, agreeableness, and conscientiousness. These tools includeone the Big-Five Personality Test, the NEO-FFI, the NEO-PI-R, and, more recently, the NEOFFI3. Nieto et al. (2017) have also attempted to create a new item pool to assess the Big Five, using a computerized adaptive test. Researchers have found that assessments can 
provide accurate measures of personality with a mere 120 items; the original NEO-PI-R contained 240 items, and the NEO-FFI contains 60 items (Nieto et al., 2017).

\section{Cross-Cultural Generalizability of the Five-Factor Model}

Researchers have found that the FFM applies to both Eastern and Western cultures, which suggests that there is a genetic component to the traits. However, it is also important to note that this research primarily included samples from large, well-educated societies (Schultz, 2015). Interestingly, in a study on a small tribal group in Bolivia, researchers did not find evidence of these factors (Schultz, 2015). Join with next para.Researchers have found evidence of all five factors in people in various cultures, and there was little difference between these traits across cultures (Allik \& Allik, 2002; Schultz, 2015).

McCrae and Costa developed the FFM using a psycho-lexical approach. This suggests that there are individual differences in the measures for people who share a common language (Allik \& Allik, 2002). However, in recent years, the popularity of the FFM has grown, leading researchers question its generalizability to other cultures and to create new instruments that incorporate culture-specific language. The use of these diverse instruments suggests that the FFM is valid in a variety of languages and cultures (Allik \& Allik, 2002).

Summary of the Theories and Models Related to Burnout According to Golden et al. (2004), much of the early research on burnout was situational or environmental. Historically, researchers believed that the nature of the environments in which people conducted their activities actively contributed to burnout. 
They considered some work environments to be unfavorable and not conducive to certain work. They believed that such severe and strenuous work environments contributed to increased exhaustion and burnout. However, Pretorius (1994) found that, after controlling for age and gender, conflict explained the most substantial variance in emotional exhaustion and depersonalization (as cited in Golden et al., 2004). When people experienced depersonalization, the quality of their service delivery decreased. This resulted in low personal accomplishment and tended to lower the efficiency levels of the workforce, resulting in reduced organizational and personal output levels.

Multiple studies have found that highly religious people have better psychological health. This is because religious people tend to trust and turn to their faith in times of conflict and desperation. Their belief in supernatural help from during stress situations is beneficial to their mental health because they tend to have fewer worries about current or future problems (Baetz et al., 2006). Baetz et al. (2006) found that higher worship frequency was associated with lower odds of psychiatric disorder. These results are encouraging for the religious community because they indicate the benefits of maintaining one's faith. Interestingly, Baetz and colleagues also found that individuals who considered spiritual values to be important (in a search for meaning, in receiving strength, and an understanding of life's difficulties) had higher odds for most psychiatric disorders. This is because, in extreme circumstances, some people become incredibly pious, to the point of almost losing the real meaning of religion and placing extreme value on it (Baetz et al., 2006).

However, other researchers have found conflicting results. For example, Pfeifer and Wately (1999) found that religiosity was not associated with either extraversion or 
neuroticism, and Glas (2007) suggested that individuals with a religious affiliation had lower anxiety levels than the general population.

\section{Synthesis of the Literature Review}

The idea of burnout has existed for a long time. In 1953, a researcher studied burnout in a psychiatric nurse (Schabracq et al., 2003). Freudenberger conceptualized burnout in terms of the emotional and physical exhaustion of workers in alternative health care organizations as a direct result of stress (as cited in Edwards, 2003).

There are several models of burnout, and researchers have studied burnout as it relates to the prevalence of aggression against healthcare providers. There is evidence that excess workload, interpersonal conflict, and mismatched values predict burnout (Gascon et al., 2013).

Researchers have widely accepted that burnout is a result of chronic job stress, and they believe that demanding jobs may elicit an emotional exhaustion response. Emotional exhaustion may be part of a negative spiral, resulting in depersonalization and increasing the need for a higher level of productivity and personal accomplishment on the job (Taris et al., 2005).

One theory of burnout, the conservation of resources theory, includes emotional intelligence, self-efficacy, organization-based self-esteem, optimism, and burnout. In Nigeria, paramilitary personnel provide services including regulating people and goods in and out of the country, border and immigration control, issuing travel documents, and correctional duties. These multiple responsibilities result in high stress levels and work overload (Ojedokun \& Idemudia, 2014). 
There is also evidence that the military has elevated levels of burnout, which lead to more mediocre job performance and lower perceived health (Vinokur et al., 2009). Researchers have long believed that lack of sleep is associated with burnout. A recent large study of nurses in hospitals showed that nurses who slept fewer than six hours had a higher risk for job strain. A generalized additive model analysis revealed a positive relationship between sleep duration, job strain, and client-related burnout (Weishan et al., 2015).

There is evidence to suggest that there is a strong relationship between personality and burnout. Some research has indicated that the Big Five personality traits correspond directly with the MBI construct of burnout (Morgan \& de Bruin, 2010). Researchers have found that emotional exhaustion is positively correlated with neuroticism and openness and that depersonalization is positively correlated with neuroticism and negatively correlated with agreeableness. Lack of personal accomplishment is also positively correlated with neuroticism, extraversion, and openness and negatively correlated with conscientiousness (Schabracq et al., 2003). In a study of applied behavior analysists, Hurt et al. (2013) found significant correlations between neuroticism and all three Maslach burnout variables. 


\section{CHAPTER 3}

\section{METHODOLOGY}

Many members of the clergy enter the ministry unprepared for its demands. Thus, when they encounter challenges arising from their requirements and allied activities they tend to experience a sense of diminished achievement. That is, although ministers often receive academic training for questions that might arise during their work they often do not fully understand the demands of the job, a deficiency that can lead to inefficiency and frustration. The impact is such that as many as 50\% of clergy have considered leaving the ministry because of burnout (Bardiau-Huys, 2014). Hence the need to understand burnout.

In this study, my goal was to explain the extent to which some characteristics of burnout such as emotional exhaustion, depersonalization, and personal accomplishment are correlated with neuroticism, openness, extraversion, agreeableness, and intellect/autonomy among protestant clergy. This chapter describes the methodology employed in achieving this end.

\section{Type of Research}

This study employed a quantitative methodology. Data were collected by means of a Likert scaled questionnaire to which respondents assigned numerical values. Though non-experimental and cross-sectional in nature, demographic variables were 
included to facilitate some statistical controls. Hence, the relationships captured should not be viewed as causal. Some demographic variables included are race, years of service, type of denomination, age, and gender.

\section{Population and Sample}

There are approximately 42,670 protestant clergy in the United States. According to the Pew Research Center, the Protestant population in the United States comprises 33\% Baptist, 10\% Pentecostal, 10\% Methodist, 8\% Lutheran, 5\% Presbyterian, 3\% Anglican/Episcopalian, 1\% Adventist, and about 30\% other denominations that are not relevant to this study. It is important to note that these numbers reflect all members of the various denominations and is not specific to clergy to any denomination. The sample included 602 clergy members from the United States who self-identified as Protestant. It consisted of 21.9\% Baptist, 21.1\% Pentecostal, 15\% Methodist, 11.6\% Evangelical, 11\% Apostolic, 8\% Lutheran, 6.1\% Presbyterian, 3.5\% Seventh-day Adventist, 2.7\% Reformed, and 0.2\% Anglican.

Participants were recruited through business cards with a website on it and through an advertisement on a Facebook page targeted to individuals who self-identified as ministers in the United States. Thus, this was a convenience and not a random sample. With the data collected the following hypotheses were tested.

\section{Hypotheses}

- Hypothesis 1: There is a significant positive relationship between the three variables of burnout (emotional exhaustion, personal accomplishment, and 
depersonalization) and the five variables of personality (neuroticism, extraversion, openness, agreeableness, and conscientiousness).

- Hypothesis 2: The personality variables of neuroticism, extraversion, openness, agreeableness, and conscientiousness are significant and independent predictors of depersonalization.

- Hypothesis 3: The personality variables of neuroticism, extraversion, openness, agreeableness, and conscientiousness are significant and independent predictors of emotional exhaustion.

- Hypothesis 4: The personality variables of neuroticism, extraversion, openness, agreeableness, and conscientiousness are significant and independent predictors of personal accomplishment.

Description of Variables

People who feel emotionally exhausted often feel like they have no power or control over what happens in their life. They may feel "stuck" or "trapped" in a situation and suffer from a lack of energy, poor sleep, and decreased motivation. An example of a statement in the MBI emotional exhaustion scale is "I feel emotionally drained from my work." In responding to the nine emotional exhaustion scale items, participants rated themselves from 0 to 6 . Overall, the lowest score a person could receive on the emotional exhaustion scale was 0 , and the highest score was 54 .

Personal accomplishment refers to the feeling of competence and achievement in one's work with others. An example of an item in the personal accomplishment scale of the MBI is "I feel I'm positively influencing other people's lives through my work." As 
with the emotional exhaustion items, participants responded on a scale from 0 to 6 . This scale included eight items, so scale scores could range from 0 to 48 .

Depersonalization refers to the extent to which a person feels distant from those he or she serves. An example of an item in the MBI depersonalization scale is "I've become more callous toward people since I took this job.” Again, participants respond on a scale from 0 to 6; with five depersonalization items, scores on this scale could range from 0 to 30 .

Neuroticism refers to character traits such as anxiety, fear, moodiness, worry, and envy. For example, one item on the neuroticism scale is "I am not a worrier." Participants respond to these items on a scale from 0 to 4 . There were a total of 12 neuroticism items, meaning that scale scores could range from 0 to 48 .

Openness to experience consists of six dimensions, including active imagination, aesthetic sensitivity, attentiveness to feelings, preference for variety, and intellectual curiosity. An example of an item on this scale is "I enjoy concentrating on fantasy or daydream and exploring all its possibilities, letting it grow and develop.” Participants responded on a scale from 0 to 4 ; with 12 scale statements, total scores could range from 0 to 48 points.

Extraversion refers to a person's tendency to be outgoing, talkative, and energetic. One item from the extraversion scale is "I like to have a lot of people around me," and participants respond on a scale from 0 to 4 . The extraversion scale had 12 statements, and total scores could range from 0 to 48 points.

Agreeableness refers to behavioral characteristics that others perceive as kind, sympathetic, cooperative, warm, and considerate. An example item from this scale is "I 
try to be courteous to everyone I meet." Participants respond to the 12 agreeableness items on a scale from 0 to 4 ; thus, scale scores could range from 0 to 48 points.

Conscientiousness refers to being thorough, careful, or vigilant. One example statement from this MBI scale is "I keep my belongings neat and clean." As with the other personality scales, participants respond on a scale from 0 to 4 , there are 12 total items, and scale scores could range from 0 to 48 points.

\section{Instrumentation}

\section{The Maslach Burnout Inventory}

The MBI is the most widely used instrument for measuring burnout in the world (Randall, 2013). Researchers have successfully used it with individuals in a wide range of helping professions. According to Randall (2013), people have not widely used the MBI with clergy because of its use of the term "client." However, in 2004, the Consulting Psychologists Press permitted the use of the MBI among the clergy. Researchers conducted a factor analysis on data from a general survey of Japanese workers (not necessarily clergy) and found little correlation between the scales of exhaustion and professional efficacy for the construct validity of the MBI. This finding implies that these two variables are distinct from one another. The researchers did find a moderate correlation between exhaustion and cynicism; after other research confirmed this correlation, cynicism and exhaustion were combined into the one category of emotional exhaustion. The MBI is also used in many industries to understand the difficulties that may lead to burnout in professionals. 
There is empirical support for the final three factors for the MBI model, emotional exhaustion, depersonalization, and professional efficacy (Taris, Schreurs, \& Schaufeli, 1999). Researchers conducted studies on the original three-factor model (which includes exhaustion, depersonalization, and professional efficacy) in Finland, the Netherlands, and Sweden (Schutte, Toppinen, Kalimo, \& Schaufeli, 2000). Through 2001, only healthy workers completed the MBI; however, the MBI may also yield data regarding symptoms of mental health disorders.

Schaufeli, Bakker, Hoogduin, Schaap, and Kladler (2001) examined the validity of the MBI among individuals who were already experiencing burnout. Their results suggested that the instrument is valid for use with this population, allowing researchers to expand the scope of the three-factor model. Using a factor analysis, the researchers also found that burnout was clinically distinct from other disorders (Schaufeli et al., 2001).

\section{The NEO-FFI-3}

The NEO-FFI-3 is a 60 -item brief form of the NEO Personality InventoryRevised (NEO-PI-R). The purpose of the NEO Inventories is to measure the FFM of personality (McCrae \& Costa, 2010). Researchers have conducted studies on the NEO Scales for over 30 years in both clinical and non-clinical samples, and they refined the toll using a combination of rational and factor analytic methods. Through this work, researchers have found that the measured facets of personality were reliable and heritable and that their developmental trends are similar across cultures (McCrae \& Costa, 2010).

Internal consistency for the NEO-FFI-3 ranged from .66 to .88. The varimaxrotated item factors correlated closely for the domain scores of adolescents and adults. In a sample of 532 adults, the coefficient alphas for the adult populations across the five 
domains were neuroticism, $\alpha=0.86$; extraversion, $\alpha=0$.79; openness, $\alpha=0.78$;

agreeableness, $\alpha=0.79$; and conscientiousness, $\alpha=0.82$. Information regarding the consistency and reliability of the NEO-FFI-3 was derived from the NEO inventories professional manual (McCrae \& Costa, 2010).

For the present study, data were collected using the 22-item MBI, the 60-item NEO-FFI-3, and eight demographic questions. Thus, the full instrument consisted of 90 multiple-choice questions

\section{Data Collection}

Approval from the Internal Review Board at Andrews University was secured for the purpose of data collection. The data was accessed by way of an online administration of the 60-item NEO-FFI-3; the 20-item MBI, and eight demographic questions.

More specifically a Facebook advertising campaign was run in which potential clergy participants were asked if they wished to participate in a research study regarding clergy burnout and personality. Participants were also recruited by way of distribution of business cards with the relevant online website address on it. This was done between July 2018 and September 2018. Before they could participate in the survey participants were asked to indicate their willingness.

The data were stored in a password protected file, and no one had access to participants' identification information. However, I did keep records of participants' internet provider (IP) addresses to ensure that participants did not submit multiple responses from the same IP address. 


\section{Data Analysis}

The data was screened for missing cases and inconsistent responding. There were no missing cases in the data. Thus, the full sets of data were available for analysis. I did not remove outliers from the data.

In analyzing the data, it was first determined whether there was a significant relationship between burnout, as measured by the MBI, and personality, as measured by the NEO-FFI-3. This was done by running a canonical correlation in SPSS. This statistical technique requires a normal distribution of the data. Join with previous paragraph)

Canonical correlation provides a joint and independent impact of the independent variables on the dependent variables. In this instance, the Big Five personality variables and the burnout variables. Canonical analysis was employed because the surveys generated data on two sets of variables. Multiple regression analyses were also conducted.

\section{Summary}

This study sought to answer the question whether personality traits, as measured by the NEO-FFI-3, predicted burnout, as measured by the MBI. Latent in the MBI measure are the variables emotional exhaustion, depersonalization, personal accomplishment while openness to experience, neuroticism, agreeableness, conscientiousness, and extraversion are nested in the NEO-FFI scale. The former, the MBI is the outcome variable with the latter the NEO-FFI and its components the independent variables. 
This study was non-experimental in that the independent variables were not manipulated across participants, and therefore no causal relationships could be assumed.

However, demographic variables were included to facilitate statistical controls. Four hypotheses were tested in this study. Hypothesis 1 posited that there would be a significant positive relationship between burnout and personality. The other three hypotheses involved the five personality factors of neuroticism, extraversion, openness, agreeableness, and conscientiousness; and it was hypothesized that they would collectively and independently predict the three individual burnout variables: feelings of personal accomplishment, depersonalization, and emotional exhaustion. 


\section{CHAPTER 4}

\section{RESULTS}

This chapter presents the data analysis of the study. The main hypothesis of this research suggests that personality traits predict burnoutamong protestant clergies.

Personality traits: neuroticism, extraversion, openness, agreeableness, and conscientiousness, were captured with the use of NEO-FFI-3 while the burnout variables: emotional exhaustion, personal accomplishment and depersonalization were measured with the use of the MBI.

To determine the association between the personality and burnout responses of participants involved in ministry (clergies) across the United States, canonical correlational analysis was employed. In presenting the results, I begin with the descriptive analysis of the variables, followed by the canonical correlation analysis. Four variables and matching hypotheses guided the study design and data analysis.

\section{Description of Participants}

Sixty-two participants responded to business cards advertising the study, and 540 participants responded to Facebook advertising.

The data was examined for normalities, such as kurtosis, skew, and outliers. Fifteen participants were eliminated because they did not meet the criteria for the study. 
Only data from participants who completed all 90 questions were retained for analysis. The final sample included 602 participants who qualified for inclusion in the study.

Participants self-reported demographic data as part of the survey. Of the 602 participants, 124 were female (20.6\%), and 478 were male (79.4\%). The number of years in ministry ranged from six to over 15 years, with 105 reporting 6-9 years (17.4\%); 127 reporting $10-15$ years (21.1\%); and 370 reporting over 15 years (61.5\%). Participant age ranged from under 21 to over 60 years of age. One person was under $21(0.2 \%), 20$ people were $22-29$ (3.3\%), 116 were 30-39 (19.3\%), 137 were $40-49$ (22.8\%), 190 were $50-59(31.68 \%)$, and 138 were 60 years of age or older $(22.9 \%)$.

For ethnicity and race, 561 people identified as Caucasian (93.2\%), 12 as Latino/Hispanic (2.0\%), four as African (0.7\%), six as American Indian (1.0\%), three as Caribbean $(0.5 \%)$, one as East Asian $(0.2 \%)$, two as Middle Eastern $(0.3 \%)$, and six as mixed $(1.0 \%)$. There was also an option to mark ethnicity and race as "other," which six participants $\operatorname{did}(0.1 \%)$.

Denominational affiliations were as follows: one participant identified as Anglican (0.2\%), 66 as Apostolic (11.0\%), 132 as Baptist (21.9\%), 70 as Evangelical Christian (11.6\%), 48 as Lutheran (8.0\%), 90 as Methodist (15\%), 121 as Pentecostal (20.1\%), 37 as Presbyterian (6.1\%), 16 as Reformed Christian (2.7\%), and 21 as Seventhday Adventists (3.5\%). 
Table 1

Description of Participants

\begin{tabular}{|c|c|c|}
\hline Variable & $N$ & $\%$ \\
\hline \multicolumn{3}{|l|}{ Gender } \\
\hline Female & 124 & 20.6 \\
\hline Male & 478 & 79.4 \\
\hline \multicolumn{3}{|l|}{ Ethnicity } \\
\hline African & 4 & 0.7 \\
\hline Native American & 6 & 1 \\
\hline Caribbean & 3 & 5 \\
\hline Caucasian & 561 & 93.2 \\
\hline East Asian & 1 & 0.2 \\
\hline Latino/Hispanic & 12 & 2 \\
\hline Middle Eastern & 2 & 0.3 \\
\hline Mixed & 6 & 1 \\
\hline \multicolumn{3}{|l|}{ Denomination } \\
\hline Anglican & 1 & 0.2 \\
\hline Apostolic & 66 & 11 \\
\hline Baptist & 132 & 21.9 \\
\hline Evangelical & 70 & 11.6 \\
\hline Lutheran & 48 & 8 \\
\hline Methodist & 90 & 15 \\
\hline Pentecostal & 121 & 21.1 \\
\hline Presbyterian & 37 & 6.1 \\
\hline Reformed & 16 & 2.7 \\
\hline Seventh-day Adventist & 21 & 3.5 \\
\hline \multicolumn{3}{|l|}{ Age } \\
\hline 21 and under & 1 & 0.2 \\
\hline $22-29$ & 20 & 3.3 \\
\hline $30-39$ & 116 & 19.3 \\
\hline $40-49$ & 137 & 22.8 \\
\hline $50-59$ & 190 & 31.6 \\
\hline 60 and Over & 138 & 22.9 \\
\hline \multicolumn{3}{|l|}{ Years involved in clergy } \\
\hline $6-9$ & 127 & 21.1 \\
\hline $10-15$ & 105 & 17.4 \\
\hline More than 15 & 370 & 61.5 \\
\hline Total & 602 & 100.0 \\
\hline
\end{tabular}




\section{Description of Variables}

Univariate descriptive statistics were calculated for each of the dependent and independent variables. In the burnout dimension, the means, ordered from highest to lowest, are personal accomplishment $(M=33.84, S D=7.949)$, emotional exhaustion ( $M$ $=25.46, S D=12.31)$, and depersonalization $(M=7.83, S D=6.064)$.

For the personality trait variables, the means, ordered from highest to lowest are agreeableness $(M=34.99, S D=5.457)$, conscientiousness $(M=31.89, S D=7.048)$, openness $(M=30.72, \mathrm{SD}=6.768)$, extraversion $(M=28.96, S D=7.438)$, and neuroticism $(M=24.71, S D=8.983)$.

Table 2

Descriptive Statistics of the Dimensions of Burnout and Personality

\begin{tabular}{|c|c|c|c|c|c|c|c|}
\hline \multirow[b]{2}{*}{ Variable } & \multirow[b]{2}{*}{$N$} & \multirow[b]{2}{*}{$M$} & \multirow[b]{2}{*}{$S D$} & \multicolumn{2}{|c|}{ Skewness } & \multicolumn{2}{|c|}{ Kurtosis } \\
\hline & & & & Statistic & $S E$ & Statistic & $S E$ \\
\hline \multicolumn{8}{|l|}{ Burnout } \\
\hline Emotional exhaustion & 602 & 25.46 & 12.310 & 0.183 & 0.100 & -0.797 & 0.199 \\
\hline Depersonalization & 602 & 7.83 & 6.064 & 0.729 & 0.100 & -0.256 & 0.199 \\
\hline Personal & 602 & 33.84 & 7.949 & -0.496 & 0.100 & -0.405 & 0.199 \\
\hline \multicolumn{8}{|l|}{ accomplishment } \\
\hline \multicolumn{8}{|l|}{ Personality } \\
\hline Neuroticism & 602 & 24.71 & 8.983 & 0.003 & 0.100 & -0.479 & 0.199 \\
\hline Extraversion & 602 & 28.96 & 7.438 & -0.204 & 0.100 & -0.268 & 0.199 \\
\hline Openness & 602 & 30.72 & 6.768 & -0.088 & 0.100 & -0.367 & 0.199 \\
\hline
\end{tabular}


Agreeableness

Conscientiousness
602

602
34.99

31.89 $\begin{array}{lll}5.457 & -0.577 & 0.100\end{array}$

$0.579 \quad 0.199$

Hypotheses Testing

One canonical correlation as well as three linear regression analyses was conducted to test the hypothesis that elements of burnout were related to personality traits. In each linear regression, the five personality variables of neuroticism, extraversion, openness to experience, agreeableness, and conscientiousness were used as predictors of each of the dependent burnout variables, emotional exhaustion, depersonalization and personal accomplishment. In total, four hypotheses were tested and found to be significant.

. Join the paragraphs.

Hypotheses Tested

Research Hypothesis 1. There is a significant relationship between the three variables of burnout (emotional exhaustion, personal accomplishment, and depersonalization) and the five variables of personality (neuroticism, extraversion, openness, agreeableness, and conscientiousness), as measured by the NEO-FFI-3.

Null hypothesis. There is no relationship between the three variables of burnout (emotional exhaustion, personal accomplishment, and depersonalization) and the five variables of personality (neuroticism, extraversion, openness, agreeableness, and conscientiousness), as measured by the NEO-FFI-3. 
A canonical correlational analysis was conducted to determine the relationship between the independent variables of personality (neuroticism, extraversion, openness, agreeableness, and conscientiousness) and the dependent variables of burnout (emotional exhaustion, personal accomplishment, and depersonalization).

The model was statistically significant, Wilks's $\lambda=0.317, F(15,1640.17)=$ 56.477, $p<0.001, R_{c}=.759, R_{c}{ }^{2}=.577$. The effect size is moderate at 0.577 .The null hypothesis was therefore rejected.

The analysis yielded three statistically significant orthogonal functions. The values of their correlation coefficients were .76 for the first function, .39 for the second, and .34 for the third. Because Functions 2 and 3 showed weak relationships between the sets of variables, and further because there is a lack of theoretical support for more relationships, only the first function in this analysis was used. To determine the correlation between the dependent variables and the respective independent variables the canonical loadings were examined.

Table 3 shows the correlation between each variable and the respective canonical variates. It presents the canonical loadings of the variables as a measure of the correlation and shared variances between the observed variables and the respective canonical construct. For the burnout variables, correlations were emotional exhaustion ( $r$ $=-.864)$, personal accomplishment $(r=.719)$, and depersonalization $(r=-.755)$. For the personality variables, the correlations were neuroticism $(r=-.899)$, extraversion $(r=$ $.670)$, agreeableness $(r=.455)$, openness $(r=.181)$, and conscientiousness $(r=.438)$. 
Table 3

Correlations Between Variables and Canonical Variates

\section{Function 1}

Variable

$B^{a} \quad r^{b}$

Burnout

Emotional exhaustion

$-.567$

$-.864$

.746

Depersonalization

$-.221$

$-.755$

.570

Personal accomplishment

.479

.719

.517

$R_{\mathrm{c}}$

.759

.577

Personality

Neuroticism

$-.719$

$-.899$

.808

Extraversion

.360

.670

.449

Openness

.118

.181

.033

Agreeableness

.136

.455

.207

Conscientiousness

.066

.438

.192

Note. $B^{a}=$ standardized function coefficient. $r^{b}=$ canonical loading of the variables. $r^{2 c}=$ squared canonical loadings. $R_{c}=$ canonical correlation. 


\section{Hypothesis 2}

Null Hypothesis 2. The independent personality variables of neuroticism, extraversion, openness, agreeableness, and conscientiousness are not significant predictors of depersonalization.

Multiple regression was performed to determine whether the independent variables of neuroticism, extraversion, openness, agreeableness, and conscientiousness predicted depersonalization. The results were significant, $F(5,596)=74.029, p<.001$; thus, the null hypothesis was rejected. The percentage of explained variance for depersonalization was $R^{2}=.383$ and adjusted $R^{2}=.378$ (see Table 4).

Table 4

Percentage of Explained Variance for Each Criterion Variable

\begin{tabular}{lcc}
\hline Criterion & $R^{2}$ & Adjusted $R^{2}$ \\
\hline Emotional exhaustion & .467 & .463 \\
Depersonalization & .383 & .378 \\
Personal accomplishment & .372 & .366 \\
\hline
\end{tabular}

Neuroticism in clergy $(\beta=0.447)$ positively predicted depersonalization. Both agreeableness $(\beta=-0.269)$ and extraversion $(\beta=-0.073)$ negatively predicted depersonalization. There were no significant relationships between depersonalization and openness or between depersonalization and conscientiousness (see Table 5). 
Table 5

Correlational Analysis Between Independent Variable Depersonalization and Personality Variables $(\mathrm{N}=602)$

\begin{tabular}{lccc}
\hline Variable & $B$ & $\beta$ & $p$ \\
\hline Neuroticism & 0.301 & 0.447 & .001 \\
Openness & --- & --- & .608 \\
Agreeableness & -0.299 & -0.269 & .001 \\
Conscientiousness & --- & --- & .841 \\
Extraversion & -0.599 & -0.073 & .041
\end{tabular}

Note. I used the beta coefficients $(\beta)$ to identify the strongest predictors of the relationship between the depersonalization and the personality variables. Significance was at the $p=.05$ level.

\section{Hypothesis 3}

Null Hypothesis 3. The independent personality variables of neuroticism, extraversion, openness, agreeableness and conscientiousness are not significant predictors of emotional exhaustion.

To test the null hypothesis, a multiple regression analysis was conducted to determine whether the independent variables neuroticism, extraversion, openness, agreeableness, and conscientiousness predicted emotional exhaustion. The results were significant, $F(5,596)=104.618, p<.001$; thus, the null hypothesis was rejected. The percentage of explained variance for emotional exhaustion was $R^{2}=.467$ and adjusted $R^{2}$ $=.463($ see Table 3$)$. Both neuroticism $(\beta=0.595)$ and conscientiousness $(\beta=0.069)$ positively predicted emotional exhaustion. Extraversion $(\beta=-0.217)$ negatively 
predicted emotional exhaustion. The percentage of explained variance for emotional exhaustion was $R^{2}=.467$ and adjusted $R^{2}=.463$. (See Table 6).

Table 6

Correlational Analysis Between Independent Variable Emotional Exhaustion and Personality Variables $(\mathrm{N}=602)$

\begin{tabular}{lccc}
\hline Variable & $B$ & $\beta$ & $p$ \\
\hline Neuroticism & 0.815 & 0.595 & $<.001$ \\
Openness & --- & --- & .202 \\
Agreeableness & --- & --- & .392 \\
Conscientiousness & 0.118 & 0.069 & .038 \\
Extraversion & -0.358 & -0.217 & $<.001$ \\
\hline
\end{tabular}

Note. I used the beta coefficients $(\beta)$ to identify the strongest predictors of the relationship between the emotional exhaustion and the personality variables. Significance was at the $p=.05$ level.

\section{Hypothesis 4}

Null Hypothesis 4. The independent personality variables of neuroticism, extraversion, openness, agreeableness, and conscientiousness are not significant predictors of personal accomplishment.

A standard multiple regression to determine whether the independent variables of neuroticism, extraversion, openness, agreeableness, and conscientiousness predicted personal accomplishment was conducted. There were significant results, $F(5,596)=$ $70.631, p<.001$; thus, I rejected the null hypothesis. The percentage of explained 
variance for emotional exhaustion was $R^{2}=.372$ and adjusted $R^{2}=.366$ (see Table 4).

Neuroticism $(\beta=-0.231)$ negatively predicted personal accomplishment. Openness $(\beta=$ $0.242)$, conscientiousness $(\beta=0.181)$, and extraversion $(\beta=0.282)$ each positively predicted personal accomplishment (see Table 7). (Join with previous paragraph)

\section{Table 7}

Correlational Analysis Between Independent Variable Personal Accomplishment and Personality Variables $(\mathrm{N}=602)$

\begin{tabular}{lccc}
\hline & $B$ & $\beta$ & $p$ \\
\hline Neuroticism & -0.204 & -0.231 & $<.001$ \\
Openness & 0.284 & 0.242 & $<.001$ \\
Agreeableness & --- & --- & .088 \\
Conscientiousness & 0.204 & 0.181 & $<.001$ \\
Extraversion & 0.301 & 0.282 & $<.001$
\end{tabular}

Note. I used the beta coefficients $(\beta)$ to identify the strongest predictors of the relationship between the personal accomplishment and the personality variables. Significance was at the $p=.05$ level.

\section{Summary of Results}

In this study, there were four hypotheses regarding the relationships between the variables. By testing these hypotheses, it was determined whether the canonical variates were significant predictors of the dependent variables and which variables shared a significant amount of variance with the canonical variates. 
Hypothesis 1 concerned the relationship between the burnout variables (emotional exhaustion, depersonalization, and personal accomplishment) and the personality variables (neuroticism, extraversion, openness, agreeableness, and conscientiousness). The results indicated that there was a significant canonical relationship between burnout and personality variates, $p<.001$. The canonical correlation $\left(R_{c}\right)$ was .76 , and the amount of shared variance between the predictors $\left(R^{2 c}\right)$ was .58 .

For the burnout variables, the beta coefficients $(\beta)$ were, from strongest to weakest, emotional exhaustion ( $\beta=-0.567)$, personal accomplishment $(\beta=0.475)$, and depersonalization $(\beta=-0.221)$. For the personality variables, the beta coefficients were, from strongest to weakest: neuroticism $(\beta=-0.719)$, extraversion $(\beta=$ $0.36)$, agreeableness $(\beta=0.136)$, openness $(\beta=0.118)$, and conscientiousness $(\beta=$ 0.066).

Hypothesis 2 concerned the relationship between the burnout variable of depersonalization and the personality variables. There were significant relationships between depersonalization and neuroticism, agreeableness, and extraversion. Neuroticism $(\beta=0.447)$ positively predicted depersonalization, and both agreeableness ( $\beta$ $=-0.269)$ and extraversion $(\beta=-0.073)$ negatively predicted depersonalization. There were no significant relationships between depersonalization and openness or between depersonalization and conscientiousness.

Hypothesis 3 concerned the relationships between the burnout variable of emotional exhaustion and the personality variables. There were significant relationships between emotional exhaustion and neuroticism, conscientiousness, and extraversion. 
Both neuroticism $(\beta=0.595)$ and conscientiousness $(\beta=.069)$ positively predicted emotional exhaustion, and extraversion $(\beta=-0.217)$ negatively predicted emotional exhaustion.

Hypothesis 4 concerned the relationships between the burnout variable of personal accomplishment and the personality variables. There were significant relationships between personal accomplishment and neuroticism, openness conscientiousness, and extraversion. Neuroticism $(\beta=-0.231)$ negatively predicted personal accomplishment. Openness $(\beta=0.242)$, conscientiousness $(\beta=0.181)$, and extraversion $(\beta=0.282)$ positively predicted personal achievement. 


\section{CHAPTER 5}

\section{SUMMARY DISCUSSION, CONCLUSIONS AND RECOMMENDATIONS}

A growing body of data suggests that ministerial demands deplete emotional, cognitive, and spiritual energies among members of the clergy.

Some have speculated about the interaction between burnout and personality (Bakker et al., 2006; Hurt et al., 2013). However, there is little research to demonstrate how personality relates to burnout in members of the clergy. Some researchers have suggested that members of the clergy have a high level of idealism, optimism, and compassion, while others have claimed that clergies experience burnout because of an interplay between narcissism and perfectionism with still others noting the importance of other issues, such as problems with bureaucracy, low administrative support, and challenging work conditions (Grosch \& Olsen, 2000).

In this chapter, an encapsulation of the previous chapters is provided. In addition

the main findings of the study are summarized and discussed, followed by a discussion of the significant relationships, limitations, implications, and conclusion of the study. 


\section{Purpose of the Study}

The purpose of the study was to examine the relationship between personality trait and burnout. Specifically, the FFM, measuring personality trait and the MBI, measuring burnout were employed to determine whether burnout among protestant clergies in the US varied by personality trait.

\section{Statement of the Problem}

According to Doolittle (2007), individuals who work in caring professions often experience burnout. There exists a large body of research on burnout, including a factor analysis supporting the concept of burnout. In recent years, researchers have raised questions about the interaction between personality and burnout.

As prominent members of a caring profession, clergy often experience burnout, characterized by emotional exhaustion. Clergy with high levels of emotional exhaustion often feel drained and discouraged. Others who reported high satisfaction stated that the ministry provided purpose and meaning to their lives (Barnard \& Curry, 2012). Miner (2007) suggested that burnout, anxiety, and depression are costly problems for clergy and that "it needs to be learned whether personal factors...can be predictive of anxiety, depression and burnout" (Miner, 2007, p. 18). Yet little research exists in this connection.

\section{Summary of the Literature Review}

The literature review conducted for this study examined past research on burnout in clergy members in the United States. A historical and philosophical overview of the 
burnout phenomenon, as well as an analysis of the theories and models of burnout are discussed.

This is followed by an exploration of the research on the relationship between personality and burnout and how burnout affects the clergy and differs by ethnicity. I summarized and analyzed both the MBI and the FFM, and described the relationship between the two. I concluded the literature review by discussing the relationship between FFM and coping, including how personality traits relate to clergy members' coping strategies.

\section{Historical and Philosophical Overview}

Psychology researchers have used the term burnout as early as 1953, beginning with an article on a psychiatric nurse (Schabracq et al., 2003). In 1969, Bradley referred to staff burnout in an article about probation officers who were running a communitybased program for juvenile delinquents (as cited in Schabracq et al., 2003, p. 383).

Views exist that Freudenberger originally coined the term burnout to describe stress-related symptoms of emotional and physical exhaustion of persons working in alternative health care institutions (Schabracq et al., 2003). However, this belief is untrue. There is evidence to suggest that there is a strong relationship between personality and burnout. Some research has indicated that the Big Five personality traits correspond directly with the MBI construct of burnout (Morgan \& de Bruin, 2010; Schabracq et al., 2003). In the Handbook of Work and Health Psychology, the authors suggested that emotional exhaustion was positively correlated with neuroticism and openness, whereas depersonalization was positively correlated with neuroticism and negatively with agreeableness. They also noted that lack of personal accomplishment was positively 
correlated with neuroticism, extraversion, and openness and negatively correlated with conscientiousness (Schabracq et al., 2003).

Bakker et al. (2006) measured the personality traits and burnout of Dutch volunteer counselors and found that only neuroticism significantly predicted emotional exhaustion. However, more recent research has suggested that there may be a stronger connection between personality and burnout. Morgan and de Bruin (2010) found that neuroticism was positively correlated with both emotional exhaustion and cynicism and negatively correlated with professional efficacy. In addition, extraversion was negatively correlated with emotional exhaustion and cynicism and positively correlated with professional efficacy. Openness to experience was positively correlated with professional efficacy, and agreeableness was negatively correlated with cynicism and positively correlated with professional efficacy. Conscientiousness was negatively correlated with emotional exhaustion and cynicism and positively correlated with professional efficacy.

Hurt et al. (2013) conducted another study examining the relationships between the same personality traits and burnout (measured by the MBI) in applied behavior analysts. They found several significant correlations between neuroticism and all three MBI scales of burnout. Extraversion and conscientiousness were negatively correlated with professional efficacy, whereas agreeableness was positively correlated with it.

In another study, Hoghwalder (2009) investigated the relationships between the personality variables of neuroticism, extraversion, and conscientiousness and the burnout variables of emotional exhaustion, depersonalization, and personal accomplishment. Interestingly, participants who scored low on neuroticism also scored low on emotional 
exhaustion, and those who scored high on neuroticism also scored high on emotional exhaustion. The author noted, "Finally, it can be seen that Neuroticism may generally be considered a vulnerability factor and extraversion and conscientiousness as protective factors for burnout” (Hoghwalder, 2009).

Researchers have found that knowledge of personality factors can safeguard from burnout, improve efficiency, and contribute to increased output. They also found that neuroticism directly contributed to depersonalization and led to decreased efficiency in service delivery. Other factors, such as extraversion and conscientiousness, were associated with higher levels of success at both personal and organizational levels.

Over the last decade, researchers have developed assessment tools for measuring spirituality, but there are several problems related to the variety of available instruments and of measured constructs. One issue is the conceptual redundancy among these new scales. Golden et al. (2004) questioned the extent to which the scales measured unique constructs and the extent to which they merely reiterated a prevalent construct. If they are merely reiterating a familiar construct, the scales do nothing more than convert personality variables into religious ones.

Virginia (1998) investigated burnout and depression among Roman Catholic, secular, religious order, and monastic priests using the MBI. However, because of the variety of religions researchers study, it is not always possible to compare results across studies. For example, Virginia (1998) compared three different kinds of priests, but the only type of priest that researchers can compare to most other clergy is the secular priest.

One important step in assessing the resources available to clergy is determining the psychological effects of religion on clergy members. Most studies on the topic have 
found that highly religious people have better psychological health. In a study conducted in Canada, Baetz et al. (2006) found that frequency of worship was negatively correlated with chances of developing a psychiatric disorder. In contrast, people who considered higher spiritual values important (in a search for meaning, giving strength, and understanding life's difficulties) were more likely to develop a psychiatric disorder. Pfeifer and Waelty (1999) found that religiosity was not associated with either extraversion or neuroticism. Glas (2007) stated that religious affiliation is related to lower anxiety levels in the general population. He conducted a comprehensive review of the literature related to religion and medicine, and almost half of the reviewed studies found lower levels of anxiety among more religious people.

Studies suggest that religious attendance and affiliation are related to improved cases of mental health status as a result of the increased social integration and support that institutionalized religion provides. (Nooney \& Woodrum, 2002). London and Wiseman (2011) found that $45 \%$ of Jewish counselors sought out therapeutic help, whereas only $22 \%$ of Arab counselors sought help.

Evans et al. (2004) found that, among childcare professionals, African American workers showed higher levels of depersonalization and emotional exhaustion than Caucasian Americans. The African American participants were also more willing to engage in stress management than the Caucasian American participants. In this study, burnout was highest among underrepresented minorities, followed by Caucasians, and then Asians. The differences between these groups were statistically significant $(p=$ .002; Primack et al., 2010). 
Summary of the Internal Structure of the MBI

The relationship between personality and burnout cuts across three different dimensions - depersonalization, emotional exhaustion, and personal accomplishment. Researchers have linked a number of personality variables, such as emotional stability, positive affectivity, self-esteem, and negative affectivity, to burnout. Different personality factors explain the various burnout dimensions.

For some helping professions, researchers defined burnout as "a negatively, indifferent or overly detached attitude to patients" (Pisanti et al., 2013, p. 698). One question on the depersonalization scale of the MBI involves clergy viewing "parishioners" as "impersonal objects" (Hills et al., 2004, p. 33). Doolittle (2007) also defined depersonalization as treating others as objects (Doolittle, 2007). Today, clergy can bring work home with them on their tablets or computers. Technology has allowed people to immerse themselves in work while avoiding personal interaction; however, such interaction is vital to emotional health. Technology can allow people to escape from ordinary relationships with church, family, and other support groups.

The Big Five/Five-Factor Model of Personality and its Relationship to Depersonalization Researchers have found a positive relationship between neuroticism and both emotional exhaustion and depersonalization (Bakker et al., 2006; Kokkinos, 2007). Miner (2007) also found that extraversion was negatively correlated with depersonalization, and Kokkinos (2007) found that there was a negative relationship between openness to experience and depersonalization. Kokkinos (2007) also found a negative relationship between conscientiousness and depersonalization. Depersonalization on the MBI was negatively correlated with the NEO factors of 
extraversion, agreeableness, and conscientiousness ( $r$ 's $=-.23,-.30$, and -.19 , respectively). Depersonalization was positively correlated with neuroticism, $r=.35$ (Rodgerson \& Piedmont, 1998).

On the MBI, the emotional exhaustion scale is associated with two factors: the general exhaustion group factor and a general burnout factor (Morgan et al., 2014). Additionally, emotional exhaustion refers to feelings of emotional overextension and of being drained by contact with others (Dietzel \& Coursey, 1998). Emotional exhaustion can lead to general exhaustion, in addition to burnout, which leads to reduced work rates and levels of success (Vinokur et al., 2009). Morgan et al. (2014) found that personal efficacy (as measured by the MBI) was negatively correlated with both emotional exhaustion and the cynicism. This suggests that individuals have low productivity levels when they experience burnout. Emotional exhaustion results from poor work environments or ineffective operational systems. Job responsibilities, increased working hours, working in poor work environments, or using ineffective operational systems with little or no leisure may contribute to poor work environments (Hoghwalder, 2009). Lack of sufficient leisure time, coupled with long working hours, resulted in emotional exhaustion and significantly lower efficiency levels, in addition to high levels of burnout. Excessive responsibilities led to overworking, exhaustion, and increased mental pressure. This resulted in mental exhaustion and eventually in decreased efficiency levels (Bakker et al., 2006).

The leading cause of increased or excess job obligations is a lack of adequately trained staff or inadequate staffing. Staffing is vital to both the efficiency and output of various industries and organizations. When only a few staff members in an organization 
possess a particular specific skill, those few staff are solely responsible for handing the organizational duties and obligations related to that skill; this leads to increased job obligations and duties without staff reinforcement. This leads to overworking the existing staff, increasing the amount of pressure placed on these individuals and leading to reduced efficiency and productivity across the organizational departments (Bakker et al., 2006).

Researchers have found that emotional exhaustion is negatively correlated with the NEO factors of extraversion $(r=-.026)$, agreeableness $(r=-.22)$, and conscientiousness $(r=-.27)$. Furthermore, emotional exhaustion is negatively correlated with neuroticism, $r=0.56$ (Rodgerson \& Piedmont, 1998).

Levels of personal accomplishment may mitigate burnout. According to Maslach, Jackson, and Leiter (2016), “the Personal Accomplishment subscale assesses feelings of competence and achievement in one's work with people" (p. 4). Furthermore, researchers have found that professionals who have higher clinical workloads have both higher levels of stress and more significant feelings of personal accomplishment (Deary et al., 1996). The personality factors of extraversion and conscientiousness both contributed to positive feelings of personal accomplishment (Deary et al., 1996; Kokkinos, 2007). Kokkinos (2007) found that the MBI dimension of personal accomplishment was positively related conscientiousness, extraversion and openness and negatively related to neuroticism.

Researchers have found significant relationships between the Big Five personality traits and coping (Roesch et al., 2006). Roesch et al. (2006) found that neuroticism was positively correlated with emotionally focused coping (emotional support) and that 
extraversion, conscientiousness, and openness were positively correlated with problemfocused coping. In addition, agreeableness was positively correlated with active coping and humor. Results from a meta-analysis of studies on personality and coping suggested that personality was weakly correlated with general coping and extraversion and conscientiousness (but not neuroticism) predicted problem-solving and cognitive restructuring (Connor-Smith \& Flachsbart, 2007).

\section{Methodology}

\section{Population and Sample}

There are approximately 42,670 Protestant clergy members in the United States. The sample of the present study included 602 clergy members from the United States who self-identified as Protestant. Participants were recruited through either a business card with the website on it or a targeted advertisement on their Facebook page. Because participants who completed the questionnaire were not randomized and did so only because of their availability and willingness to do so, this sample is appropriately labelled a convenience sample.

\section{Research Questions}

The following research questions guided the study:

- Research Question1: Is there a significant canonical correlation between burnout and personality?

- Research Question 2: Do the personality variables of neuroticism, extraversion, openness, agreeableness, and conscientiousness predict emotional exhaustion? 
- Research Question 3: Do the personality variables of neuroticism, extraversion, openness, agreeableness, and conscientiousness predict depersonalization?

- Research Question 4: Do the personality variables of neuroticism, extraversion, openness, agreeableness and conscientiousness predict personal accomplishment?

\section{Research Design}

A correlational research design was employed to investigate the association between the independent and dependent variables of the study. As such, this study was non-experimental since it is based on a non-random sample and no manipulation of the variables. Data were collected with the aid of a questionnaire comprising of the instruments: MBI, NEO-FFI-3, as well as selected demographic items including ethnicity, age, denominational type, years of service, and gender, serving as controls.

\section{Summary Findings}

\section{Research Question 1}

Is there a significant canonical correlation between burnout and personality?

\section{Hypothesis}

There is a significant relationship between the three variables of burnout (emotional exhaustion, personal accomplishment, and depersonalization) and the five 
variables of personality (neuroticism, extraversion, openness, agreeableness, and conscientiousness), as measured by the NEO-FFI-3.

\section{Results}

There is a strong correlation between burnout and personality, $p<.001$. The significance level suggests there is little chance of error in this conclusion. The correlation is .759 and the effect size was .577 . The model was statistically significant, Wilks's $\lambda=0.317, F(15,1640.17)=56.477, p<0.001, R_{c}=.759, R_{c}{ }^{2}=.577$. The effect size is moderate at 0.577 . The null hypothesis is rejected.

\section{Discussion}

The main finding of this canonical correlation is that burnout, as measured by the MBI, and personality as measured by the five-factor model, are correlated. The suggestion that these constructs would be connected was suggested by Moran $\&$ de Bruin, 2010 and Schabracq et al., 2003. In fact, The Handbook of Work and Health Psychology indicates that emotional exhaustion is correlated positively with neuroticism and openness, while depersonalization is correlated positively with agreeableness (Schabracq, Winnubst, \& Cooper, 2003). Schabracq etl al, (2003) also suggested that lack of personal accomplishment has a positive correlation to neuroticism, extraversion, and openness and has a negative relationship with conscientiousness.

Alarcon (2009) reported that several personality variables are related to burnout. These variables include extraversion, conscientiousness and agreeableness. In 2006, Bakker et al. measured personality traits and burnout among Dutch volunteer counselors and found that only neuroticism significantly predicted emotional exhaustion. However, more recent research among Applied Behavior Analysists showed that neuroticism was 
related to all three subscales of burnout (emotional exhaustion, depersonalization and personal accomplishment) and extraversion and conscientiousness correlated negatively with professional efficacy while agreeableness correlated positively with professional Efficacy (Hurt et al,. 2013). Hoghwalder (2009) found that people who scored low on neuroticism also scored low on emotional exhaustion, and those who scored high on neuroticism also scored high on emotional exhaustion.

This hypothesis did not answer the question of which variables would be associated with which other variables. Rather, it asked whether the constructs of Personality and Burnout are significantly correlated. This correlation was conducted because the research suggested that there would be a correlation between the constructs.

Although Bakker et al. (2006) suggested that only neuroticism was associated with emotional exhaustion in his research, this present study suggests that there is more going on between burnout and personality than only those two variables of neuroticism and emotional exhaustion being related.

\section{Research Question 2}

Do the personality variables of neuroticism, extraversion, openness, agreeableness, and conscientiousness predict emotional exhaustion?

\section{Hypothesis 2}

The independent personality variables of neuroticism, extraversion, openness, agreeableness, and conscientiousness significantly predict depersonalization.

Results

Neuroticism, agreeableness and extraversion all significantly predicted depersonalization. Openness to experience and conscientiousness were not significant 
predictors. Neuroticism $(\beta=.447)$ positively predicted depersonalization, whereas agreeableness and extraversion negatively predicted depersonalization $(\beta=-.269$ and .073 , respectively). The null hypothesis was rejected.

\section{Discussion}

It is unsurprising that neuroticism, which refers to character traits such as anxiety, fear, moodiness, worry, and envy, positively predicted depersonalization (i.e., feeling distant from those one serves). Also, because agreeableness refers to behaviors that are kind, sympathetic, cooperative, warm and considerate and extraversion refers to a person's tendency to be outgoing, talkative and energetic, agreeableness and extraversion may be buffers against depersonalization. Researchers have found that openness to experience is negatively correlated with depersonalization; however, this relationship did not emerge in the present study. It is unclear why openness to experience was not a significant predictor of depersonalization, though it is possible the relationship may have approached significance with a larger sample.

Kokkinos (2007) found that conscientiousness was associated with depersonalization and personal accomplishment and that higher scores on neuroticism was related to increased scores on depersonalization and emotional exhaustion in teachers. This was supported by Miner (2007) who found that extraversion was correlated with depersonalization. Kokkinos (2007) also suggested that there may be a negative relationship between openness to experience and depersonalization, as well as a negative relationship between conscientiousness and depersonalization. Rodgerson \& Piedmont (1998) found that depersonalization was negatively correlated with agreeableness, conscientiousness and neuroticism. 
The results of this study suggest that neuroticism, agreeableness and extraversion are all significant predictors of depersonalization. These results did not support the findings of Kokkinos (2007) and Rodgerson and Piedmont (1998) which indicated that conscientiousness would be negatively correlated with depersonalization. Rather, conscientious was not a significant predictor of depersonalization in this study. However, extraversion was a significant predictor of depersonalization, supporting Miner (2007) who indicated that extraversion would be correlated with depersonalization.

Some possible reasons for some of these differences may be related to the populations that were studied. Kokkinos (2007) studied teachers. However, Rodgerson and Piedmont (1998) studied clergy. Another possibility for the differences between these studies may be sampling differences or the sample size of this study. As sample size increases, the chance of finding a significant result increase. So, although conscientiousness was not a significant predictor of depersonalization in this study, possibly it would be significant if there were more participants.

The results indicated that three of the personality traits were significant predictors of depersonalization. This finding is in line with other work, which found a positive relationship between neuroticism and depersonalization (Bakker et al., 2006) and a negative relationship between extraversion and depersonalization (Miner, 2007).

\section{Research Question 3}

Do the personality variables of neuroticism, extraversion, openness, agreeableness, and conscientiousness, predict emotional exhaustion? 


\section{Hypothesis 3}

The independent personality variables of neuroticism, extraversion, openness, agreeableness, and conscientiousness are significant predictors of emotional exhaustion.

\section{Results}

Both neuroticism $(\beta=0.595)$ and conscientiousness $(\beta=0.069)$ positively predicted emotional exhaustion. Extraversion $(\beta=-0.217)$ negatively predicted emotional exhaustion. The percentage of explained variance for emotional exhaustion was $R^{2}=.467$ and adjusted $R^{2}=.463$. The null hypothesis was rejected.

\section{Discussion}

It is not surprising that neuroticism positively predicted emotional exhaustion. Conscientiousness, which refers to being thorough, careful, or vigilant, might naturally predict emotional exhaustion. Also, extraversion was a negative predictor of emotional exhaustion. This finding suggests that, in the helping professions, people who enjoy being around others (extraverts) would be less likely to be emotionally exhausted because of their work. Other researchers have suggested that the use of coping strategies, such as spirituality and relationships with colleagues, are associated with low levels of emotional exhaustion in healthcare workers (Molavynejad, Babazadeh, Bereihi, \& Cheraghian, 2019)

People who are more neurotic tend to feel more emotional exhaustion. People who are conscientious spend a great deal of energy making sure that work is done in a thorough manner; they are also careful and vigilant, which requires a great deal of energy. This tends to create emotional exhaustion. Hoghwalder (2009) stated that emotional exhaustion results from a poor work environment, ineffective operational 
systems, or both; these working conditions may arise from factors such as multiple job responsibilities, increased work hours, and/or lack of leisure.

The results align with those of studies on individuals in other professions.

Although the sample of ministers included in this research was a convenience sample, the results from this sample were in line with the results of other work in this area.

Because other researchers have found similar findings, this study provides further evidence of the relationships between personality and burnout and expands these findings to ministers.

\section{Research Question 4}

Do the personality variables of neuroticism, extraversion, openness, agreeableness, and conscientiousness predict personal accomplishment?

\section{Hypothesis}

The independent personality variables of neuroticism, extraversion, openness, agreeableness, and conscientiousness, are significant predictors of personal accomplishment.

\section{Results}

The results were significant, $F(5,596)=70.631, p<.001$. The percentage of explained variance for emotional exhaustion was $R^{2}=.372$ and adjusted $R^{2}=.366$. Neuroticism $(\beta=-0.231)$ negatively predicted personal accomplishment. Openness $(\beta=$ 0.242 ), conscientiousness $(\beta=0.181)$, and extraversion $(\beta=0.282)$ positively predicted personal accomplishment. The null hypothesis was rejected. 


\section{Discussion}

The term personal accomplishment refers to the feeling of competence and achievement in one's work with people. The results of the present study suggest that a person has a higher sense of personal accomplishment if they are open to new experiences, conscientious, and extraverted. On the other hand (and in line with other studies), neuroticism (anxiety, fear, moodiness, worry, and envy) was a negative predictor of feelings of personal accomplishment.

The review of the literature revealed the following results. Two personality factors from the FFM, extraversion, and conscientiousness, contribute to positive feelings of personal accomplishment (Deary et al., 1996; Kokkinos, 2007). Kokkinos (2007) found that the personal accomplishment was positively related to conscientiousness, extraversion, and openness and negatively related to neuroticism. Molavynejad et al. (2019) also found that people who are open to experience and agreeable have high levels of flexibility and tend to be responsible individuals and schedule their work well.

The similarity between the results of the present study and those in the literature increases understanding of the variables. The findings of this study match those in the literature, with the exception that agreeableness was not a significant predictor of burnout. One possible reason for this discrepancy is that the sample size was not large enough.

\section{An Analysis of the Findings}

It appears that few clergy members have received training on the effects of burnout or how to avoid burnout. This is unfortunate because research has shown that 
there are certain aspects of a person's personality that predispose one to burnout. Hypothesis 1 concerned the relationship between burnout variables (emotional exhaustion, depersonalization, personal accomplishment) and personality variables (neuroticism, extraversion, openness, agreeableness, conscientiousness). A significant correlation between the factors of burnout and personality was found, $p<.001$. The effect size was moderate at 0.577 .

Because there were three dependent variables, the model produced three significant orthogonal functions that were all correlated at $p<.001$. Model 1 was correlated at .76. Model 2 was correlated at .39 and Model 3 at .34 .

The literature does not suggest other, latent variables. However, it is possible that there exist other aspects of burnout might be of relevance. Both Factors 2 and 3 had a small amount of shared variance (.15 and .12 , respectively). Because there was no evidence in the literature of another latent variable and because of the small levels of shared variances, I did not interpret Factors 2 or 3.

Among the burnout variables, emotional exhaustion was the most reliable measure of burnout $(\beta=-0.567)$, followed by personal accomplishment $(\beta=0.475)$ and depersonalization $(\beta=-0.221)$.

For the FFM personality variables, as measured by the NEO-FFI-3, the strongest measure of the personality construct was neuroticism $(\beta=-0.719)$, followed by extraversion $(\beta=0.36)$, agreeableness $(\beta=0.136)$, openness $(\beta=0.118)$ and conscientiousness $(\beta=0.066)$.

In Hypothesis 2, it was proposed that there was a significant relationship between depersonalization and the five personality variables. Neuroticism $(\beta=0.447)$ positively 
predicted depersonalization, and agreeableness $(\beta=-0.269)$ and extraversion $(\beta=-0.073)$ negatively predicted depersonalization.

In Hypothesis 3, it was predicted that there would be significant relationships between the personality variables and emotional exhaustion. People who reported higher rates of emotional exhaustion also reported higher levels of neuroticism $(\beta=0.595)$ and conscientiousness $(\beta=0.038)$ but a lower level of extraversion $(\beta=-0.217)$.

The last personality variable in this study was personal accomplishment. It was hypothesized that there would be a significant positive relationship between personal accomplishment and burnout. The personal accomplishment scale assessed feelings of competence and achievement in one's work with people (Morgan \& de Bruin, 2010). Neuroticism $(\beta=-0.231)$ negatively predicted personal achievement, and openness $(\beta=$ $0.242)$, conscientiousness $(\beta=0.181)$, and extraversion $(\beta=0.282)$ positively predicted personal achievement.

Because the results of this study were consistent with those of other studies on person-centered professions, it was anticipated that ministers experienced similar symptoms of burnout as other individuals who work with people. Some of the personality variables did not reach significance, which limited the interpretation of this research. However, most of the variables did reach significance, and the overall results were similar to those found in studies of other helping professions.

Notably, it is possible that extraversion mitigates feelings of emotional exhaustion, which may be useful for ministers. Ministers who are not as extraverted will need to be more aware of their sense of personal burnout. 


\section{Limitations of the Study}

One limitation of this study is the use of survey data. The reliability of survey data may depend on the honesty of participants to provide accurate and honest answers to the items/questions. Also certain answer options may be interpreted differently by respondents.

Another limitation is the use of convenience sampling to select participants. According to Ayele et al. (2017), "convenience sampling is a type of nonprobability sampling in which people are sampled simply because they are convenient sources of data for researchers." This is only a limitation in that it is impossible to study the whole population; thus, researchers must use a large enough sample size to allow for the generalizability of results.

A third limitation of the study was the representativeness of the study sample. Although I tried to get an ethnically representative sample (through an advertisement on Facebook), only about five percent of respondents came from minority populations.

\section{Implications for Further Research}

The results of this study suggest that many clergy members experience burnout. It might be useful to conduct a follow-up study to test whether burnout awareness training may mitigate burnout in the clergy. Differences on the effects of burnout among clergy, based on ethnic and racial background, should also be explored.

\section{Implications for Practice}

Clinicians need to realize that as a person becomes burned out, their feelings of personal accomplishment diminish. This can turn into a vicious circle. Thus, it should be 
a requirement that clergy members take a certain amount of time off each year to go to conferences, take vacations, or experience times of solitude to rejuvenate their resources. Such time off will help clergy members to be more productive, increase their feelings of personal accomplishment, and therefore decrease burnout. 


\section{APPENDIX A}

NEO-FFI-3

ID\#

Name Age _ Sex _ Today's date

1. I am not a worrier.

2. I like to have a lot of people around me.

3. I enjoy concentrating on a fantasy or daydream and exploring all its possibilities, letting it grow and develop.

4. I try to be courteous to everyone I meet.

5. I keep my belongings neat and clean.

6. At times I have felt bitter and resentful.

7. I laugh easily.

8. I think it's interesting to learn and develop new hobbies.

9. At times I bully or flatter people into doing what I want them to.

10. I'm pretty good about pacing myself so as to get things done on time.

11. When I'm under a great deal of stress, sometimes I feel like I'm going to pieces.

12. I prefer jobs that let me work alone without being bothered by other people.

13. I am intrigued by the patterns I find in art and nature.

14. Some people think I'm selfish and egotistical.

15. I often come into situations without being fully prepared.

16. I rarely feel lonely or blue. 
17. I really enjoy talking to people.

18. I believe letting students hear controversial speakers can only confuse and mislead them.

19. If someone starts a fight, I'm ready to fight back.

20. I try to perform all the tasks assigned to me conscientiously.

21. I often feel tense and jittery.

22. I like to be where the action is.

23. Poetry has little or no effect on me.

24. I'm better than most people, and I know it.

25. I have a clear set of goals and work toward them in an orderly fashion.

26. Sometimes I feel completely worthless.

27. I shy away from crowds of people.

28. I would have difficulty just letting my mind wander without control or guidance.

29. When I've been insulted, I just try to forgive and forget.

30. I waste a lot of time before settling down to work.

31. I rarely feel fearful or anxious.

32. I often feel as if I'm bursting with energy.

33. I seldom notice the moods or feelings that different environments produce.

34. I tend to assume the best about people.

35. I work hard to accomplish my goals.

36. I often get angry at the way people treat me.

37. I am a cheerful, high-spirited person.

38. I experience a wide range of emotions or feelings. 
39. Some people think of me as cold and calculating.

40. When I make a commitment, I can always be counted on to follow through. 


\title{
MASLACH BURNOUT INVENTORY
}

\section{Maslach Burnout Inventory ${ }^{\mathrm{TM}}$}

Instruments and Scoring Guides

\section{Forms: General, Human Services, \& Educators}

Christina Maslach, Susan E. Jackson, Michael P. Leiter, Wilmar B. Schaufeli, Richard L.

\section{Schwab}

\author{
Published by Mind Garden \\ info@mindgarden.com \\ Www.mindgarden.com
}

\section{MBI-General Survey}

Wilmar B. Schaufeli, Michael P. Leiter, Christina Maslach, \& Susan E. Jackson The purpose of this survey is to discover how staff members view their job, and their reactions to their work.

\section{Instructions}

On the following page are 16 statements of job-related feelings. Please read each statement carefully and decide if you ever feel this way about your job. If you have never had this feeling, write the number " 0 " (zero) in the space before the statement. If you have had this feeling, indicate how often you feel it by writing the number (from 1 to 6 ) that best describes how frequently you feel that way. An example is shown below. 
If you never feel depressed at work, you would write the number " 0 " (zero) under the heading "How Often." If you rarely feel depressed at work (a few times a year or less), you would write the number "1." If your feelings of depression are fairly frequent (a few times a week but not daily), you would write the number "5."

\section{MBI-General Survey}

\begin{tabular}{|c|c|c|c|c|c|c|c|}
\hline \multirow[t]{2}{*}{$\begin{array}{l}\text { How } \\
\text { often }\end{array}$} & 0 & 1 & 2 & 3 & 4 & 5 & 6 \\
\hline & Never & $\begin{array}{c}\text { A few times a } \\
\text { year or less }\end{array}$ & $\begin{array}{c}\text { Once a month } \\
\text { or less }\end{array}$ & $\begin{array}{l}\text { A few } \\
\text { times } \\
\text { a month }\end{array}$ & $\begin{array}{l}\text { Once a } \\
\text { week }\end{array}$ & $\begin{array}{c}\text { A few times a } \\
\text { week }\end{array}$ & $\begin{array}{c}\text { Every } \\
\text { day }\end{array}$ \\
\hline
\end{tabular}


How Often

0-6 Statements

1. _ $\quad$ I feel emotionally drained from my work.

2. _ $\quad$ I feel used up at the end of the workday.

3. _ $\quad$ I feel tired when I get up in the morning and have to face another day on the job.

4. _ $\quad$ Working all day is really a strain for me.

5. _ _ I can effectively solve the problems that arise in my work.

6. - $\quad$ I feel burned out from my work.

7. _ $\quad$ I feel I am making an effective contribution to what this organization does.

8. _ $\quad$ I have become less interested in my work since I started this job.

9. _ $\quad$ I have become less enthusiastic about my work.

10. _ $\quad$ In my opinion, I am good at my job.

11. _ _ I feel exhilarated when I accomplish something at work.

12. _ I I have accomplished many worthwhile things in this job.

13. _ $\quad$ I just want to do my job and not be bothered.

14. _ I have become more cynical about whether my work contributes anything.

15. _ I doubt the significance of my work.

16. _ $\quad$ At my work, I feel confident that I am effective at getting things done. 


\section{STUDY WELCOME PAGE}

This survey instrument is being used to gather data for a research project through Andrews University as partial requirement for a $\mathrm{PhD}$ degree. This study focuses on the relationship between personality, burnout, and ethnicity among Protestant clergy in the United States. Your answers will remain anonymous and confidential throughout their use in this study. You do have the option to have your results in the burnout inventory and personality testing emailed to you as well as the final results of the study if you choose to include your email and request the results. This will be done automatically by our software during the data gathering and tabulation phase, and your confidentiality is still assured.

Thank you for your involvement. Your participation is greatly appreciated. Please answer all questions in this study — there are about 90 questions - otherwise your data cannot be used in this analysis. 82 of the questions have simple answers to select from. The remaining questions are used to identify your demographic background and level of ministry experience.

It typically takes less than 15 minutes to complete the survey. It must be completed in one sitting. We recommend using a tablet or full computer. Attempts from a phone seem to leave unanswered questions and incomplete data we cannot use.

\section{Study Terms and Requirements}

You must be a minister in a Protestant organization with at least 6 years of experience in the ministry. You must agree to participate in this survey and study, 
understanding that your answers will remain confidential. If you do not wish to participate, click the ' $\mathrm{x}$ ' in the top corner of your browser to exit.

I agree to the terms and to participate in this study.

[Participants had to click a button that said "Begin Survey" to start the survey] 


\section{REFERENCES}

Alarcon, G., Eschleman, K., \& Bowling, N. (2009). Relationships between personality variables and burnout: A meta-analysis. Work \& Stress, 23(3), 244-263. doi:10.1080/02678370903282600

Allik, I. U., \& Allik, I. (2002). The five-factor model of personality across cultures. Springer Science \& Business Media.

Amigo, I., Asensio, E., Menéndez, I., Redondo, S., \& Ledesma, J. A. (2014). Working in direct contact with the public as a predictor of burnout in the banking sector. 26(2), 222-226. doi:10.7334/psicothema2013.282

Baetz, M., Bowen, R., Jones, G., \& Koru-Sengul, T. (2006). How spiritual values and worship attendance relate to psychiatric disorders in the Canadian population. 51(10), 654-661.

Bagby, R. M., Gralnick, T. M., Al-Dajani, N., \& Uliaszek, A. A. (2016). The role of the five-factor model in personality assessment and treatment planning. Clinical Psychology: Science \& Practice, 23(4), 365-381. doi:10.1111/cpsp.12175

Bakker, A. B., van der Zee, K. I., Lewig, K. A., \& Dollard, M. F. (2006). The relationship between the Big Five personality factors and burnout: A study among volunteer counselors. Journal of Social Psychology, 146(1), 31-50. Retrieved from http://search.ebscohost.com/login.aspx?direct=true \&db=a9h\&AN=19547543\&sit $\mathrm{e}=$ ehost-live

Bardiau-Huys, L. (2014). Sustaining pastoral ministry: Denominations must assume their responsibilities. JEPTA: Journal of the European Pentecostal Theological Association, 34(1), 61-76. Retrieved from http://search.ebscohost.com/login.aspx?direct=true \&db=a9h\&AN=95042586\&sit $\mathrm{e}=$ ehost-live

Barnard, L., \& Curry, J. (2012). The relationship of clergy burnout to self-compassion and other personality dimensions. Pastoral Psychology, 61(2), 149-163. doi:10.1007/s1 1089-011-0377-0

Berry, A., Francis, L., Rolph, J., \& Rolph, P. (2012). Ministry and stress: Listening to Anglican clergy in Wales. Pastoral Psychology, 61(2), 165-178. doi:10.1007/s11089-011-0388-x

Bidlan, J. S., \& Sihag, A. (2014). Occupational stress, burnout, coping and emotional intelligence: Exploring gender differences among different occupational groups of healthcare professionals. Indian Journal of Health \& Wellbeing, 5(1), 149-154. Retrieved from 
http://search.ebscohost.com/login.aspx?direct=true\&db=a9h\&AN=97600638\&sit $\mathrm{e}=$ ehost-live

Blanch, A. (2007). Integrating religion and spirituality in mental health: The promise and the challenge. Psychiatric Rehabilitation Journal, 30(4), 251.

Bornstein, S. M., \& Smith, A. F. (1996). The puzzles of leadership.

Bowler, M. C., Bowler, J. L., \& Cope, J. G. (2012). Further evidence of the impact of cognitive complexity on the five-factor model. Social Behavior \& Personality: An International Journal, 40(7), 1083-1097. doi:10.2224/sbp.2012.40.7.1083

Carmona, C., Buunk, A. P., Peiró, J. M., Rodríguez, I., \& Bravo, M. J. (2006). Do social comparison and coping styles play a role in the development of burnout? Crosssectional and longitudinal findings. Journal of Occupational \& Organizational Psychology, 79(1), 85-99. doi:10.1348/096317905X40808

Chandler, D. (2009). Pastoral burnout and the impact of personal spiritual renewal, resttaking, and support system practices. Pastoral Psychology, 58(3), 273-287. doi:10.1007/s1 1089-008-0184-4

Choi, H., Puig, A., Kim, K., Lee, S., \& Lee, S. M. (2014). Examining differential effects of internal and external resources on counselor burnout symptoms in South Korea. Journal of Employment Counseling, 51(1), 2-15. doi:10.1002/j.21611920.2014.00037.x

Connor-Smith, J. K., \& Flachsbart, C. (2007). Relations between personality and coping: a meta-analysis. 93(6), 1080.

Córdoba, L., Tamayo, J. A., González, M. A., Martínez, M. I., Rosales, A., \& Barbato, S. H. (2011). Adaptation and validation of the Maslach Burnout Inventory-Human Services Survey in Cali, Colombia. 42(3), 286-293. Retrieved from http://search.ebscohost.com/login.aspx?direct=true \&db=a9h\&AN=67127327\&sit $\mathrm{e}=$ ehost-live

Costa, P. T., \& McCrae, R. R. (1992). Revised NEO Personality Inventory and NEO Five-Factor Inventory: Professional manual. Odessa, FL: Psychological Assessment Resources.

Croucher, R., Marcenes, W. S., Torres, M. C. M. B., Hughes, F., \& Sheiham, A. (1997). The relationship between life-events and periodontitis: A case-control study. Journal of Clinical Periodontology, 24(1), 39-43. doi:10.1111/1600051X.ep13476617

Davis, R. D., \& Millon, T. (1993). The five-factor model for personality disorders: Apt or misguided? Psychological Inquiry, 4(2), 104. Retrieved from 
http://search.ebscohost.com/login.aspx?direct=true\&db=a9h\&AN=7396566\&site $=$ ehost-live

Deary, I. J., Blenkin, H., Agius, R. M., Endler, N. S., Zealley, H., \& Wood, R. (1996). Models of job-related stress and personal achievement among consultant doctors. 87(1), 3-29.

Demerouti, E. (2015). Strategies used by individuals to prevent burnout. European Journal of Clinical Investigation, 45(10), 1106-1112. doi:10.1111/eci.12494

DePree, M. (2011). Leadership is an art. Crown Business.

Dietzel, L. C., \& Coursey, R. D. (1998). Predictors of emotional exhaustion among nonresidential staff persons. Psychiatric Rehabilitation Journal, 21(4), 340. Retrieved from http://search.ebscohost.com/login.aspx?direct=true \&db=a9h\&AN=644646\&site= ehost-live

Doolittle, B. R. (2007). Burnout and coping among parish-based clergy. Mental Health, Religion \& Culture, 10(1), 31-38. doi:10.1080/13674670600857591

Edwards, W. D. (2003). A study on various factors and their relationship to burnout among Seventh-day Adventist clergy. (Doctoral dissertation). Retrieved from ProQuest Dissertations and Theses Database. (UMI No. 3098152)

Evans, G. D., Bryant, N. E., Owens, J. S., \& Koukos, K. (2004). Ethnic differences in burnout, coping, and intervention acceptability among childcare professionals. Child \& Youth Care Forum, 33(5), 349-371. doi:10.1023/B:CCAR.0000043040.54270.dd

Flanders, W. (2017). Biographies of Robert R McCrae and Paul T Costa Jr. Retrieved from http://www.flandershealth.us/personality-2/biographies-of-robert-r-mccraeand-paul-t-costa-jr.html

Frederick, T. V., Dunbar, S., \& Thai, Y. (2018). Burnout in Christian perspective. Pastoral Psychology, 67(3), 267-276. doi:10.1007/s11089-017-0799-4

Fye, H. J., Gnilka, P. B., \& McLaulin, S. E. (2018). Perfectionism and school counselors: Differences in stress, coping, and burnout. Journal of Counseling \& Development, 96(4), 349-360. doi:10.1002/jcad.12218

Gascon, S., Leiter, M. P., Andrés, E., Santed, M. A., Pereira, J. P., Cunha, M. J., . . . Martínez-Jarreta, B. (2013). The role of aggressions suffered by healthcare workers as predictors of burnout. Journal of Clinical Nursing, 22(21/22), 31203129. doi:10.1111/j.1365-2702.2012.04255.x 
Golden, J., Piedmont, R. L., Ciarrocchi, J. W., \& Rodgerson, T. (2004). Spirituality and burnout: An incremental validity study. Journal of Psychology and Theology, 32, $115-125$.

Goodman, E., \& Boss, R. W. (2002). The phase model of burnout and employee turnover. 25.

Grosch, W. N., \& Olsen, D. C. (2000). Clergy burnout: An Integrative approach. Journal of Clinical Psychology, 56(5), 619-632. Retrieved from

http://search.ebscohost.com/login.aspx?direct=true\&db=a9h\&AN=3283982\&site $=$ ehost-live

Hills, P., Francis, L. J., \& Rutledge, C. J. F. (2004). The factor structure of a measure of burnout specific to clergy, and its trial application with respect to some individual personal differences. Review of Religious Research, 27-42.

Hoghwalder, J. (2009). Burnout among Torgersen's eight personality types. Social Behavior \& Personality: An International Journal, 37(4), 467-479. Retrieved from http://search.ebscohost.com/login.aspx?direct=true \&db=a9h\&AN=44531921\&sit $\mathrm{e}=$ ehost-live

Hurt, A. A., Grist, C. L., Malesky, L. A., \& McCord, D. M. (2013). Personality traits associated with occupational 'burnout' in ABA therapists. Journal of Applied Research in Intellectual Disabilities, 26(4), 299-308. doi:10.1111/jar.12043

International, U. P. C. (2013). Organizational flow chart.

Justice, J. A., \& Garland, D. R. (2010). Dual relationships in congregational practice: Ethical guidelines for congregational social workers and pastors. Social Work \& Christianity, 37(4), 437-445. Retrieved from http://search.ebscohost.com/login.aspx?direct=true\&db=a9h\&AN=55558046\&sit $\mathrm{e}=$ ehost-live

Knox, S., Virginia, S. G., Thull, J., \& Lombardo, J. P. (2005). Depression and contributors to vocational satisfaction in Roman Catholic secular clergy. 54(2), $139-155$.

Kokkinos, C. M. (2007). Job stressors, personality and burnout in primary school teachers. 77(1), 229-243.

Lee, C. (2010). Dispositional resiliency and adjustment in Protestant pastors: A pilot study. Pastoral Psychology, 59(5), 631-640. doi:10.1007/s1 1089-010-0283-x 
Lee, R. T., Seo, B., Hladkyj, S., Lovell, B. L., \& Schwartzmann, L. (2013). Correlates of physician burnout across regions and specialties: A meta-analysis. Human Resources for Health, 11(1), 1-16. doi:10.1186/1478-4491-11-48

London, H. B., \& Wiseman, N. B. (2011). Pastors at greater risk. Gospel Light Publications.

Lynam, D. R., \& Miller, J. D. (2015). Psychopathy from a basic trait perspective: The utility of a five-factor model approach. Journal of Personality, 83(6), 611-626. doi:10.1111/jopy.12132

Mac Giolla, E., \& Kajonius, P. (2017). Personality traits across countries: Support for similarities rather than differences. PLOS ONE, 12(6), 1-13. doi:10.1371/journal.pone. 0179646

Maslach, C., Schaufeli, W. B., \& Leiter, M. P. (2001). Job burnout. Annual Review of Psychology, 52(1), 397. Retrieved from http://search.ebscohost.com/login.aspx?direct=true $\& \mathrm{db}=\mathrm{a} 9 \mathrm{~h} \& \mathrm{AN}=4445608 \&$ site $=$ ehost-live

McCrae, R. R., \& Costa, P. T. (2010). NEO Inventories professional manual. Lutz, FL: Psychological Assessment Resources.

Merhi, R., Sánchez-Elvira-Paniagua, Á., \& Palací, F. J. (2018). The role of psychological strengths, coping strategies and well-being in the prediction of academic engagement and burnout in first-year university students. 15(2), 51-67. doi:10.5944/ap.15.2.21831

Miner, M. H. (2007). Burnout in the first year of ministry: Personality and belief style as important predictors. Mental Health, Religion \& Culture, 10(1), 17-29. doi:10.1080/13694670500378017

Miner, M. H., Dowson, M., \& Sterland, S. (2010). Ministry orientation and ministry outcomes: Evaluation of a new multidimensional model of clergy burnout and job satisfaction. Journal of Occupational \& Organizational Psychology, 83(1), 167188. Retrieved from

http://search.ebscohost.com/login.aspx?direct=true \&db=a9h\&AN=48996501\&sit $\mathrm{e}=$ ehost-live

Mitchell Legg, P. (2012). The work of Christian education in the seminary and the church: Then (1812) and now (2012). Interpretation: A Journal of Bible \& Theology, 66(4), 423-433. doi:10.1177/0020964312451420

Molavynejad, S., Babazadeh, M., Bereihi, F., \& Cheraghian, B. (2019). Relationship between personality traits and burnout in oncology nurses. Journal of Family Medicine \& Primary Care, 8(9), 2898-2902. doi:10.4103/jfmpc.jfmpc_423_19 
Montero-Marín, J., \& García-Campayo, J. (2010). A newer and broader definition of burnout:Validation of the "Burnout Clinical SubtypeQuestionnaire (BCSQ-36)." BMC Public Health, 10, 302-310. Retrieved from $\mathrm{http}: / /$ search.ebscohost.com/login.aspx?direct=true $\& \mathrm{db}=\mathrm{a} 9 \mathrm{~h} \& \mathrm{AN}=52038926 \&$ sit $\mathrm{e}=$ ehost-live

Montero-Marín, J., Prado-Abril, J., Carrasco, J. M., Asensio-Martínez, Á., Gascón, S., \& García-Campayo, J. (2013). Causes of discomfort in the academic workplace and their associations with the different burnout types: a mixed-methodology study. BMC Public Health, 13(1), 1-24. doi:10.1186/1471-2458-13-1240

Montero-Marin, J., Prado-Abril, J., Piva Demarzo, M. M., Gascon, S., \& GarcíaCampayo, J. (2014). Coping with stress and types of burnout: Explanatory power of different coping strategies. PLOS ONE, 9(2), 1-9. doi:10.1371/journal.pone.0089090

Morgan, B., \& de Bruin, K. (2010). The relationship between the big five personality traits and burnout in South African university students. South African Journal of Psychology, 40(2), 182-191. Retrieved from $\mathrm{http}: / /$ search.ebscohost.com/login.aspx?direct=true $\& \mathrm{db}=\mathrm{a} 9 \mathrm{~h} \& \mathrm{AN}=51471905 \&$ sit $\mathrm{e}=$ ehost-live

Morgan, B., de Bruin, G. P., \& de Bruin, K. (2014). Operationalizing burnout in the Maslach Burnout Inventory-Student Survey: Personal efficacy versus personal inefficacy. South African Journal of Psychology, 44(2), 216-227. doi:10.1177/0081246314528834

Mueller, C. W., \& McDuff, E. M. (2002). 'Good' jobs and 'bad' jobs: Differences in the clergy employment relationship. Review of Religious Research, 44(2), 150-168. Retrieved from http://search.ebscohost.com/login.aspx?direct=true \&db=a9h\&AN=8748235\&site $=$ ehost-live

Nieto, M. D., Abad, F. J., Hernández-Camacho, A., Garrido, L. E., Barrada, J. R., Aguado, D., \& Olea, J. (2017). Calibrating a new item pool to adaptively assess the Big Five. 29(3), 390-395. doi:10.7334/psicothema2016.391

Noh, H., Chang, E., Jang, Y., Lee, J., \& Lee, S. (2016). Suppressor effects of positive and negative religious coping on academic burnout among Korean middle school students. Journal of Religion \& Health, 55(1), 135-146. doi:10.1007/s10943-015$0007-8$

Nooney, J., \& Woodrum, E. (2002). Religious coping and church-based social support as predictors of mental health outcomes: Testing a conceptual model. Journal for the Scientific Study of Religion, 41(2), 359-368. 
Ojedokun, O., \& Idemudia, E. S. (2014). Burnout among paramilitary personnel in Nigeria: A perspective from conservation of resources theory. South African Journal of Psychology, 44(1), 106-117. doi:10.1177/0081246313516256

Parker, P., \& Martin, A. (2011). Clergy motivation and occupational well-being: Exploring a quadripolar model and its role in predicting burnout and engagement. Journal of Religion \& Health, 50(3), 656-674. doi:10.1007/s10943-009-9303-5

Pisanti, R., Lombardo, C., Lucidi, F., Violani, C., \& Lazzari, D. (2013). Psychometric properties of the Maslach Burnout Inventory for Human Services among Italian nurses: A test of alternative models. Journal of Advanced Nursing, 69(3), 697707. doi:10.1111/j.1365-2648.2012.06114.x

Pooler, D. (2011). Pastors and congregations at risk: Insights from role identity theory. Pastoral Psychology, 60(5), 705-712. doi:10.1007/s11089-011-0356-5

Primack, B. A., Dilmore, T. C., Switzer, G. E., Bryce, C. L., Seltzer, D. L., Li, J., . . . Rubio, D. M. (2010). Brief report: Burnout among early career clinical investigators. 3(4), 186-188.

Randall, K. J. (2013). Clergy burnout: Two different measures. Pastoral Psychology, 62(3), 333-341.

Riccelli, R., Toschi, N., Nigro, S., Terracciano, A., \& Passamonti, L. (2017). Surfacebased morphometry reveals the neuroanatomical basis of the five-factor model of personality. Social Cognitive \& Affective Neuroscience, 12(4), 671-684. doi:10.1093/scan/nsw175

Rodgerson, T. E., \& Piedmont, R. L. (1998). Assessing the incremental validity of the religious problem-solving scale in the prediction of clergy burnout. 517-527.

Roesch, S. C., Wee, C., \& Vaughn, A. A. (2006). Relations between the Big Five personality traits and dispositional coping in Korean Americans: Acculturation as a moderating factor. International Journal of Psychology, 41(02), 85-96.

Saijo, Y., Chiba, S., Yoshioka, E., Kawanishi, Y., Nakagi, Y., Itoh, T., . . Yoshida, T. (2014). Effects of work burden, job strain and support on depressive symptoms and burnout among Japanese physicians. International Journal of Occupational Medicine \& Environmental Health, 27(6), 980-992. doi:10.2478/s13382-0140324-2

Schabracq, M. J., Winnubst, J. A. M., \& Cooper, C. L. (2003). The handbook of work and health psychology. John Wiley \& Sons.

Schaufeli, W. B., Bakker, A. B., Hoogduin, K., Schaap, C., \& Kladler, A. (2001). On the clinical validity of the Maslach Burnout Inventory and the burnout measure. 
Psychology \& Health, 16(5), 565. Retrieved from http://search.ebscohost.com/login.aspx?direct=true \&db=a9h\&AN=5461014\&site $=$ ehost-live

Schaufeli, W. B., Taris, T. W., \& van Rhenen, W. (2008). Workaholism, burnout, and work engagement: Three of a kind or three different kinds of employee wellbeing? Applied Psychology: An International Review, 57(2), 173-203. doi:10.1111/j.1464-0597.2007.00285.x

Schultz, S. A. (Ed.). (2015). Theories of Personality (11th ed.). Boston, MA: Cengage Learning.

Schutte, N., Toppinen, S., Kalimo, R., \& Schaufeli, W. (2000). The factorial validity of the Maslach Burnout Inventory-General Survey (MBI-GS) across occupational groups and nations. Journal of Occupational \& Organizational Psychology, 73(1), 53-66. Retrieved from http://search.ebscohost.com/login.aspx?direct=true\&db=a9h\&AN=2942081\&site $=$ ehost-live

Scott, G., \& Lovell, R. (2015). The Rural Pastors Initiative: Addressing isolation and burnout in rural ministry. Pastoral Psychology, 64(1), 71-97. doi:10.1007/s11089-013-0591-z

Selzer, E. H. (2008). Effectiveness of a seminary's training and mentoring program and subsequent job satisfaction of its graduates. Journal of Research on Christian Education, 17(1), 25-53. doi:10.1080/10656210801967309

Sihag, A., \& Bidlan, J. S. (2014). Coping with occupational stress and burnout in healthcare. Indian Journal of Positive Psychology, 5(3), 325-328. Retrieved from http://search.ebscohost.com/login.aspx?direct=true\&db=a9h\&AN=99729927\&sit $\mathrm{e}=$ ehost-live

Spencer, J., Winston, B., \& Bocarnea, M. (2012). Predicting the level of pastors' risk of termination/exit from the church. Pastoral Psychology, 61(1), 85-98. doi:10.1007/s11089-011-0410-3

Sylwia, Z. A., Maciej, K., \& Maria, Z. A. (2018). The Big Five and burnout among teachers: the moderating and mediating role of self-Efficacy. Polish Psychological Bulletin.

Tanner, M., \& Zvonkovic, A. (2011). Forced to leave: Forced termination experiences of Assemblies of God clergy and its connection to stress and well-being outcomes. Pastoral Psychology, 60(5), 713-726. doi:10.1007/s11089-011-0339-6

Taris, T. W., Le Blanc, P. M., Schaufeli, W. B., \& Schreurs, P. J. G. (2005). Are there causal relationships between the dimensions of the Maslach Burnout Inventory? A 
review and two longitudinal tests. Work \& Stress, 19(3), 238-255. doi:10.1080/02678370500270453

Taris, T. W., Schreurs, P. J. G., \& Schaufeli, W. B. (1999). Construct validity of the Maslach Burnout Inventory-General Survey: A two-sample examination of its factor structure and correlates. Work \& Stress, 13(3), 223-237. doi:10.1080/026783799296039

Trull, T. J. (2012). The five-factor model of personality disorder and DSM-5. Journal of Personality, 80(6), 1697-1720. doi:10.1111/j.1467-6494.2012.00771.x

Vinokur, A. D., Pierce, P. F., \& Lewandowski-Romps, L. (2009). Disentangling the relationships between job burnout and perceived health in a military sample. Stress \& Health: Journal of the International Society for the Investigation of Stress, 25(4), 355-363. doi:10.1002/smi.1264

Virginia, S. G. (1998). Burnout and depression among Roman Catholic secular, religious, and monastic clergy. Pastoral Psychology, 47(1), 49-67.

Wanwen, D. A. I., Xiaoyan, C., Arnulf, J. K., \& Meijuan, D. A. I. (2014). Consequences of family interference with work: The roles of emotional exhaustion, service sabotage, and negative affectivity. Social Behavior \& Personality: An International Journal, 42(10), 1613-1627. doi:10.2224/sbp.2014.42.10.1613

Weishan, C., Yue Leon, G., Yu-Ju, H., Chiu-Yueh, Y., \& Shu-Chu Shiao, J. (2015). Short sleep duration is dose-dependently related to job strain and burnout in nurses: A cross sectional survey. International Journal of Nursing Studies, 52(1), 297-306. doi:10.1016/j.ijnurstu.2014.09.003

Widiger, T. A., \& Trull, T. J. (1997). Assessment of the five-factor model of personality. Journal of Personality Assessment, 68(2), 228. Retrieved from http://search.ebscohost.com/login.aspx?direct=true \&db=a9h\&AN=6382604\&site $=$ ehost-live

You, S., \& Yoo, J. (2016). Evaluation of the spiritual well-being scale in a sample of Korean adults. Journal of Religion \& Health, 55(4), 1289-1299. doi:10.1007/s10943-015-0010-0

Zech, C., \& Gautier, M. L. (2004). Catholic parish organizational structure and parish outcomes. Journal for the Scientific Study of Religion, 43(1), 141-150. doi:10.1111/j.1468-5906.2004.00223.x 
